\title{
บusisersaly
}

\section{Vowel reduction in Russian: No phonetics in phonology}

losad, P. (2012). Vowel reduction in Russian: No phonetics in phonology. Journal of Linguistics, 48(3), $521-571$. https://doi.org/10.1017/S0022226712000102

Link to publication record in Ulster University Research Portal

\section{Published in:}

Journal of Linguistics

Publication Status:

Published (in print/issue): 01/11/2012

DOI:

10.1017/S0022226712000102

\section{Document Version}

Publisher's PDF, also known as Version of record

\section{General rights}

Copyright for the publications made accessible via Ulster University's Research Portal is retained by the author(s) and / or other copyright owners and it is a condition of accessing these publications that users recognise and abide by the legal requirements associated with these rights.

\section{Take down policy}

The Research Portal is Ulster University's institutional repository that provides access to Ulster's research outputs. Every effort has been made to ensure that content in the Research Portal does not infringe any person's rights, or applicable UK laws. If you discover content in the Research Portal that you believe breaches copyright or violates any law, please contact pure-support@ulster.ac.uk. 


\section{Journal of Linguistics}

http://journals.cambridge.org/LIN

Additional services for Journal of Linguistics:

Email alerts: $\underline{\text { Click here }}$

Subscriptions: Click here

Commercial reprints: $\underline{\text { Click here }}$

Terms of use : $\underline{\text { Click here }}$
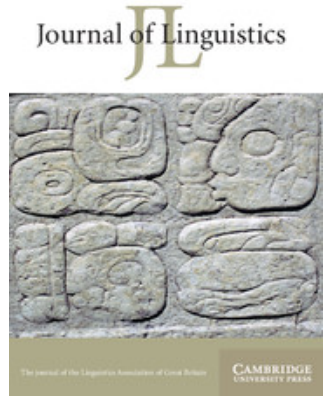

\section{Vowel reduction in Russian: No phonetics in phonology}

PAVEL IOSAD

Journal of Linguistics / Volume 48 / Issue 03 / November 2012, pp 521 - 571

DOI: $10.1017 /$ S0022226712000102, Published online:

Link to this article: http://journals.cambridge.org/abstract_S0022226712000102

How to cite this article:

PAVEL IOSAD (2012). Vowel reduction in Russian: No phonetics in phonology. Journal of Linguistics, 48, pp 521-571 doi:10.1017/S0022226712000102

Request Permissions : $\underline{\text { Click here }}$ 
J. Linguistics 48 (20I2), 52I-57I. (C) Cambridge University Press $20 \mathrm{I} 2$ doi:I0.IOI7/S0022226712000I02 First published online I2 April 2012

\title{
Vowel reduction in Russian: No phonetics in phonology
}

\author{
PAVEL IOSAD \\ University of Tromsø/Center for Advanced Study in Theoretical Linguistics
}

(Received 8 November 20I0; revised 9 January 20I2)

Much recent work in phonology concentrates on the role of sonority in the phenomenon of vowel reduction, capitalizing on two facts: that reduction involves raising and/or shortening and that higher vowels and schwa are normally interpreted as having low sonority. This paper presents a different approach to vowel reduction in Standard Russian. It is proposed that the apparent sonority-driven effects in Russian are epiphenomenal. In particular, reduction to schwa is outside the domain of phonological computation in Russian, being an artifact of reduced duration. Other types of neutralization arising in vowel reduction are potentially amenable to a sonority-based analysis, but I argue that current approaches to sonority-driven reduction suffer from representational shortcomings. When these shortcomings are rectified, however, sonority is unnecessary as an explicit factor in vowel reduction: standard markedness mechanisms suffice to explain the data.

The phenomenon of vowel reduction has been the focus of much recent work in phonology, and several proposals have been put forward to account for vowel reduction in Russian (both Modern Standard Russian and dialectal varieties). In line with a general functionalist trend, Crosswhite (2000, 200I) proposes that perception- and sonority-driven constraints are responsible for vowel reduction, and Padgett (2004) and Padgett \& Tabain (2005) explore the role of dispersion. De Lacy (2006) and Hermans (2008) also propose sonority-based accounts of reduction phenomena, though their proposals are less explicitly grounded in functional considerations. Finally, recent work

[I] Versions of this paper were presented at the November Seminar in Russian and the Laboratory Phonology course workshop (both at the University of Tromsø, November 2008 and May 2009, respectively), the Third Scandinavian Ph.D. Conference in Linguistics and Philology (University of Bergen, June 2009) and the Seventh European Conference on Formal Description of Slavic Languages (University of Potsdam, December 2009). I thank the audiences at these fora for their valuable feedback and discussion, in particular Abby Cohn, John Kingston, Gjert Kristoffersen, Margje Post, and Anton Zimmerling. Comments by Bruce Morén-Duolljá and two anonymous referees for the Journal of Linguistics have greatly enhanced both content and presentation. The paper has also benefited from discussions with Sergei Knyazev, Tore Nesset, and Evgeny Shaulskiy. I remain solely responsible for any and all shortcomings. 
by Barnes $(2006,2007)$ addresses the issue of the division of labour between the phonological and phonetic components of grammar (see also the discussion in Kingston 2007).

In this paper I propose that the correct choice of phonological representations allows us to eliminate functional considerations such as dispersion and sonority as factors relevant for the phonological computation of Russian reduction. I show that reduction to schwa, which is potentially a sonority-reducing process, is properly outside the domain of phonological computation. With respect to other processes involved in vowel reduction, sonority-based constraints succeed in deriving the resulting surface inventories, but fail to explain the patterns of faithfulness constraint violation. I propose that phonological vowel reduction in Russian is due only to positional faithfulness/markedness effects, if the representations are correct. I present an analysis in terms of the Parallel Structures Model of feature geometry (Morén 2003, 2006, 2007; Youssef 2010), and argue for the superiority of a substance-free approach to the phonology of vowel reduction.

The organization of this paper is as follows. In Section I, I describe the facts of Russian vowel reduction. Section 2 contains a short overview of the model I am using, and presents the representational assumptions underlying the account and an analysis of the patterns in terms of Optimality Theory. The aim of Section 3 is a comparison of the account proposed in the present paper with other explanations of Russian vowel reduction. Section 4 concludes.

\section{VOWEL REDUCTION IN RUSSIAN}

The term 'vowel reduction' with reference to Modern Russian is traditionally used to describe a range of neutralization patterns in unstressed syllables. I retain the traditional name, even though it might be something of a misnomer, since this process can actually lead to the appearance of highersonority vowels.

In this paper I concentrate on contemporary Central Standard Russian, essentially as spoken by educated Moscow speakers, abstracting away from both dialects and other varieties of Standard Russian, as well as from older norms which are often prominent in the literature.

\section{I.I The facts, take one}

The outcome of vowel reduction in Russian is defined by three independent variables: the identity of the underlying segment, its position within the word and the palatalization or lack thereof of the consonant preceding the vowel. Table I presents a slightly simplified version of the Russian consonant 


\begin{tabular}{|l|c|c|c|c|c|c|c|c|c|c|}
\hline Manner & \multicolumn{2}{|c|}{ Labial } & \multicolumn{2}{c|}{ Dental } & \multicolumn{2}{c|}{ Postalveolar } & \multicolumn{2}{c|}{ Palatal } & \multicolumn{2}{c|}{ Velar } \\
\hline Voiceless stop & $\mathrm{p}$ & $\mathrm{p}^{\mathrm{j}}$ & $\mathrm{t}$ & $\mathrm{t}^{\mathrm{j}}$ & & & & & $\mathrm{k}$ & $\mathrm{k}^{\mathrm{j}}$ \\
\hline Voiced stop & $\mathrm{b}$ & $\mathrm{b}^{\mathrm{j}}$ & $\mathrm{d}$ & $\mathrm{d}^{\mathrm{j}}$ & & & & & $\mathrm{g}$ & $\mathrm{g}^{\mathrm{j}}$ \\
\hline Voiceless fricative & $\mathrm{f}$ & $\mathrm{f}^{\mathrm{j}}$ & $\mathrm{s}$ & $\mathrm{s}^{\mathrm{j}}$ & $\mathrm{s}^{\mathrm{w}}$ & $\int^{\mathrm{j}_{\mathrm{r}}}$ & & & $\mathrm{x}$ & $\mathrm{x}^{\mathrm{j}}$ \\
\hline Voiced fricative & $\mathrm{v}$ & $\mathrm{v}^{\mathrm{j}}$ & $\mathrm{z}$ & $\mathrm{z}^{\mathrm{j}}$ & $\mathrm{z}^{\mathrm{w}}$ & {$\left[3^{\mathrm{j}}:\right]$} & $\mathrm{j}$ & & & \\
\hline Voiceless affricate & & & $\mathrm{ts}$ & & & $\mathrm{f}^{\mathrm{j}}$ & & & & \\
\hline Nasal & $\mathrm{m}$ & $\mathrm{m}^{\mathrm{j}}$ & $\mathrm{n}$ & $\mathrm{n}^{\mathrm{j}}$ & & & & & & \\
\hline Lateral & & & $\mathrm{t}$ & $\mathrm{l}^{\mathrm{j}}$ & & & & & & \\
\hline Rhotic & & & $\mathrm{r}$ & $\mathrm{r}^{\mathrm{j}}$ & & & & & & \\
\hline
\end{tabular}

Table I

Russian consonant inventory.

inventory. For more details of the Russian phonetic system, the reader is referred to standard overviews such as Jones \& Ward (I969) and Timberlake (2004). Table I excludes some detail of the variation (for instance, in the case of [v] and [i]), and ignores some obstruents which only appear as a result of voicing assimilation. Since these are never followed by a vowel, they are irrelevant to the present study.

The exact number of distinctive vowel segments in Russian is, famously, the subject of longstanding discussion. In this paper I assume that the inventory of stressed vowels in Russian consists of the five vowels /i u e o a/. What is often described as the high central unrounded vowel $/ \dot{\mathbf{t}} / \mathrm{is}$ in complementary distribution with [i]. I assume that it is not a phonological segment. Following Padgett (200I, 2004) and Padgett \& Tabain (2005), I interpret the [i] used in transcription as the effect of strong velarization on consonants preceding the front vowel (though, as discussed below, I disagree with Padgett on the precise phonological interpretation). ${ }^{2}$

Traditionally, Russian vowel reduction is described as a three-term system: apart from stressed vowels, there are two sub-inventories depending on the position in the word. Crosswhite (2000) terms them 'moderate' and

[2] The 'diphthongal' character of '[i]' has been known to Russian phoneticians since at least Tomson (1905). For the contrary view, largely based on a specific analysis of morphological alternations, see e.g. Plapp (I996), Rubach (2000), Blumenfeld (2003). The morphological arguments advanced by these scholars for $/ \dot{\mathbf{i}} /$ are addressed by Padgett (20II), Iosad \& Morén-Duolljá (20I2). 
'radical' reduction positions, and I follow this terminology here. The contexts for moderate reduction are as follows:

- Moderate reduction is found in the syllable immediately preceding the stressed one (the 'first pretonic').

- Onsetless syllables, irrespective of their position relative to stress, block radical reduction and exhibit the moderate pattern. ${ }^{3}$

- Unstressed phrase-final open syllables exhibit a gradient effect: moderate reduction is possible but not compulsory in this position.

- Timberlake (2004: Section 2.2.7) claims that if a hiatus consists of two /a/ or /o/ vowels (in any combination), then both of these vowels only undergo moderate reduction (note that the second would fall under the onsetless syllable clause). However, he does not a give a reference, and some sources contain contradictory examples (for instance, Timberlake has [в.e] in the word sootnošenie 'proportion', but Kasatkin 2003 writes [ə.๖] in the same word, implying radical reduction of the first vowel in hiatus).

Radical reduction is best described as the elsewhere case: in other words, it happens in syllables with onsets which are not stressed and do not immediately precede the stressed syllable. An often-used mnemonic is the so-called 'Potebnya's formula': if I means radical reduction, 2 means moderate reduction, 3 means no reduction and the acute accent indicates stress, the distribution of the reduction 'grades' can be described by the formula II 23 II.

\section{I.I.I Moderate reduction: Non-palatalized context}

The high vowels $/ \mathrm{i} /$ and $/ \mathrm{u} /$ (the former traditionally transcribed as [i] in the non-palatalized context) are not subject to phonological changes in unstressed position. However, they are significantly centralized, and consequently I transcribe them as [i] and []ㅜ. Examples are given in (I) and (2).

(I) (a) [dirkə] 'hole (diminutive)'

(b) [dịtra] 'hole'

(2) (a) ['rutfikə] 'hand (diminutive)'

(b) [rợ'ka] 'hand'

Probably the most prominent feature of the Russian vowel reduction system is the neutralization of $/ \mathrm{o} /$ and $/ \mathrm{a} /$. Both of these segments, when

[3] Sources are inconsistent as to whether moderate reduction happens in all onsetless syllables or only word- or utterance-initial ones. I follow Timberlake (2004), Barnes (2007) in taking the former to be correct. 
in unstressed position, surface as an [a]-like sound, the transcription of which has been a contentious subject. The traditional symbol is $[\Lambda]$, similar to the STRUT vowel in English Received Pronunciation; this is advanced, for example, by Jones \& Ward (1969). More recent sources, notably Padgett \& Tabain (2005) and Barnes $(2006,2007)$ in the West, use $[\mathrm{e}]$ on the basis of their phonetic findings. ${ }^{4}$ This question is specifically discussed by Kasatkina (2005), who claims that the pronunciation of [ $\mathrm{r}]$ is characteristic of Moscow and the surrounding areas, and of varieties of Standard Russian spoken in territories where the local dialects neutralize the contrast between $/ \mathrm{a} /$ and $/ \mathrm{o} /$ at least in some positions. The pronunciation of $[\Lambda]$, on the other hand, is characteristic of Standard Russian as spoken in territories where the local dialect lacks any neutralization between /a/ and /o/. This includes Northern Russia (with, importantly, St Petersburg) and large territories in the Urals and Siberia; the same pronunciation is said to be used by Russian speakers in Ukraine. Since this paper concentrates on Standard Russian, and more specifically on Moscow Russian, I follow latest practice in transcribing the outcome of neutralization of $/ a /$ and $/ \mathrm{o} /$ as $[\mathrm{e}]$. Examples are shown in (3) and (4).

(3) (a) ['davni'ij] 'ancient'

(b) [dev'no] 'long ago'

(4) (a) ['kot] 'cat'

(b) $[\mathrm{ke}$ 'ta] 'cat (gen.sg.)'

The facts of moderate reduction of /e/ after non-palatalized consonants are somewhat difficult to ascertain. In the native Russian lexicon, $/ \mathrm{e} /$ is not encountered after non-palatalized consonants other than $\left[\mathrm{s}^{\mathrm{w}}\right],\left[\mathrm{z}^{\mathrm{w}}\right]$, and [ts]: the so-called 'unpaired' or 'immutable' (Timberlake 2004) ones, which do not have a palatalized counterpart. These cases are treated in Section I.I.4 below. However, many borrowings exhibit a non-palatalized pronunciation before /e/, and these words most often still undergo reduction. ${ }^{5}$ Where they do, in the modern norm /e/ neutralizes with /i/ to become [i] ; essentially, there is no difference in the behaviour of /e/ across the non-palatalized and palatalized contexts (see below on /e/ in the palatalized context).

[4] Russian sources traditionally use $[\Lambda]$. In many newer sources, the notation $\left[\mathrm{a}^{\curvearrowright}\right]$ is used, which seems to correspond fairly closely to $[\mathrm{p}]$.

[5] See Comrie et al. (1996), Timberlake (2004) for discussion of the lack of palatalization and relevant references. Generally, as words become nativized, there is a tendency for the consonant to palatalize before/e/, but this is by no means an absolute generalization. 


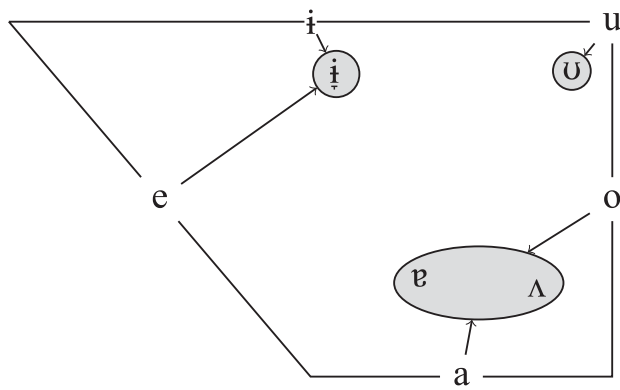

Figure I

Moderate reduction, non-palatalized context.

(5) (a) [fe'netï̈kə] 'phonetics'

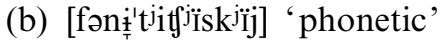

Vowels in onsetless syllables pattern with vowels following non-palatalized consonants, in that the strong coarticulatory effects associated with palatalized consonants (Kochetov 2002) are absent.

In terms of vowel reduction, the 'non-palatalized' and onsetless contexts pattern together, in that /o/ and /a/ neutralize with each other but not with /e/ or $/ \mathrm{i} /$ (as they do following palatalized consonants, see below). The behaviour of /e/ also seems to demonstrate neutralization with /i/, though examples with alternations are extremely hard to come by, since most /e/-initial words are borrowings, and stress is consistent across the paradigm, so that there are no stress-related alternations. However, unstressed initial (orthographic) /e/ is normally realized as [I], as (6) shows.

(6) $\left[\mathrm{I}^{\prime} \mathrm{tas}^{\mathrm{w}}\right]$ 'floor' (French étage)

A schematic representation of moderate reduction following non-palatalized consonants is given in Figure I.

\section{I.I.2 Moderate reduction: Palatalized context}

More contrasts are neutralized following palatalized consonants, than in the non-palatalized context. Specifically, in newer forms of Central Standard Russian all vowels except / $\mathrm{u} /$ are realized as [I], i.e. identically with unstressed /i/. This is demonstrated by the following examples:

(7) (a) $\left[n^{j} \mathrm{os}\right]$ 'he carried'

(b) $\left[\mathrm{n}^{\mathrm{j}} \mathrm{s}\right.$ 'ła] 'she carried'

(8) (a) ['p'atij] 'five'

(b) $\left[\mathrm{p}^{\mathrm{j}} \mathrm{I}^{\prime} \mathrm{t}_{\mathrm{i}}\right]$ 'five (gen.sg.)' 


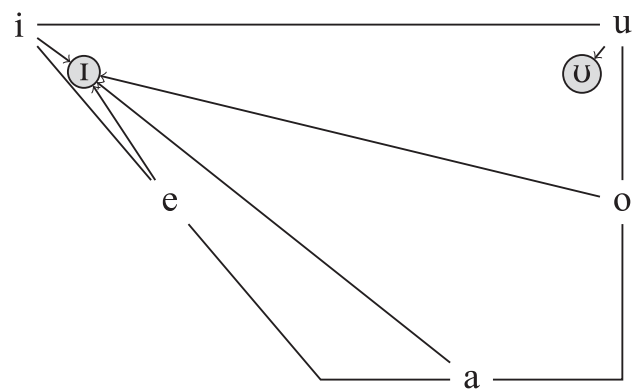

Figure 2

Moderate reduction, palatalized context.

(9) (a) [rez'dieł] 'divide (n.)'

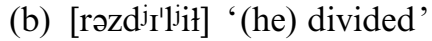

(Io) (a) ['piit] '(he) drank'

(b) $\left[\mathrm{p}^{\mathrm{j}} \mathrm{I}^{\prime} \mathrm{Ta}\right]$ '(she) drank'

The vowel /u/ does not neutralize, although, like /i/, it is significantly centralized (and fronted due to coarticulatory effects):

(II) (a) [']judis] 'people'

(b) [lị̛t'skoj] 'people's (adj.)'

In older versions of the norm (and in some dialects), only /e/, /a/ and /o/ are neutralized in this context, and the outcome of this neutralization remains distinct from /i/ (often transcribed as something like [ie]). However, in modern educated pronunciation the two-term system seems to be prevalent; for an overview, see Comrie, Stone \& Polinsky (I996), and see discussion of Padgett \& Tabain's (2005) results below. In this paper, I concentrate on the newer norm.

A schematic representation of moderate reduction in the palatalized context is given in Figure 2.

\section{I.I.3 Radical reduction}

In radical reduction, more contrasts are neutralized: the modern norm is that all vowels except $/ \mathrm{u} /$ neutralize. Following non-palatalized consonants (recall that radical reduction is impossible in onsetless contexts), all vowels are realized as a schwa, as demonstrated in the following examples. Note that there is no difference between paired and unpaired (i.e. [ $\left.\mathrm{s}^{\mathrm{w}}\right]$, [ $\left.\mathrm{z}^{\mathrm{w}}\right]$, and [ts]) non-palatalized consonants in this instance.

(I2) (a) ['sat] 'garden'

(b) [səde'vot] 'gardener' 
(I3) (a) ['dom] 'house'

(b) [dəme'voj] 'house sprite'

(I4) (a) $\left[\mathrm{z}^{\mathrm{w} e t} \mathrm{ft}^{\mathrm{j}}\right]$ 'burn'

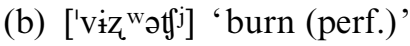

(I5) (a) ['dim] 'smoke'

(b) [dəme'xot] 'stovepipe'

(I6) (a) ['pusk] 'launch'

(b) ['vipüsk] 'issue'

Following palatalized consonants, the situation is essentially the same: all vowels neutralize except for $/ \mathrm{u} /$, though in this case the pattern of neutralization is identical to that found in moderate reduction in the non-palatalized context. The outcome of the reduction is normally transcribed in Russian-language literature as [b], implying that it is essentially a variant of the schwa following a palatalized consonant. When IPA is used (mainly outside Russia), the sound is normally transcribed as [I], thus collapsing the distinction between the outcome of this neutralization in moderate and radical reduction positions. This is technically warranted, since a vowel's position in the word defines to which Cyrillic character the graphical [I] corresponds. For clarity, however, I use [i]] where the distinction

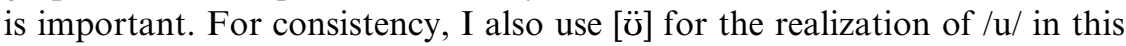
position.

(I7) (a) ['pjati] 'five'

(b) [p'ïtt'tfjok] 'five-ruble coin (dim.)'

(I8) (a) ['ljes] 'forester'

(b) [lï̈se'vot] 'forester'

(i9) (a) ['1 ' ot $]$ 'ice'

(b) [jï̈jis'noj] 'icy'

(20) (a) $\left[\mathrm{p}^{\mathrm{jit}} \mathrm{i}\right]$ 'drink'

(b) [piritij)r'voj] 'potable'

(2I) (a) ['fj'udə] 'marvel'

(b) [t ${ }^{j} \ddot{\left.\text { üd} \mathrm{j}^{\mathrm{I}} \mathrm{I} s \mathrm{~s}\right]}$ 'marvels'

Again, older descriptions insist on distinguishing between the two high vowels and a third vowel to which all non-high vowels are neutralized, such that, for example, výžat' 'squeeze dry' (from žát' 'squeeze') and výžit' 'survive' (from žit' 'live') are not homophonous (following Russian tradition, the acute accent in transliteration represents stress). Only two-vowel sub-inventories are present in the modern norm 

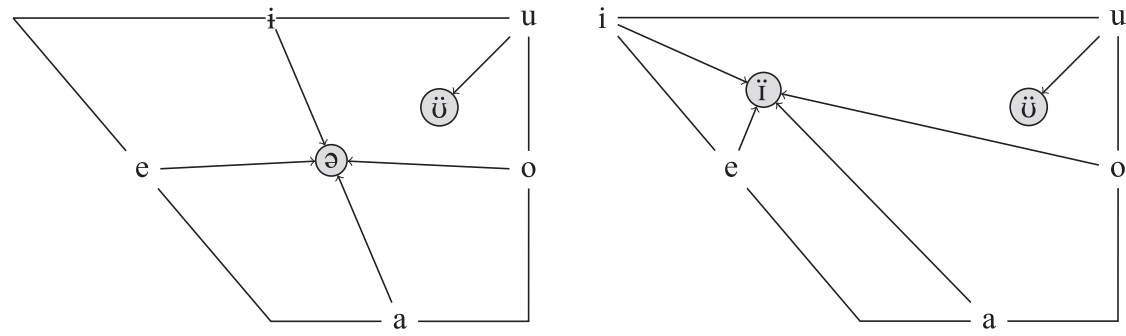

Figure 3

Radical reduction. Left panel: Non-palatalized context; right panel: Palatalized context.

on which I concentrate here. A schematic representation is given in Figure $3 .^{6}$

\section{I.I.4 Complications}

The realization of unstressed non-high vowels following the 'unpaired' nonpalatalized consonants $\left[\mathrm{S}^{\mathrm{w}}\right],\left[\mathrm{z}^{\mathrm{w}}\right]$, and [ts] deviates from the system described above. In the older norm, all these consonants consistently behave exactly like palatalized ones, in that all non-high vowels neutralize to a sound written $\left[\dot{\mathrm{i}}^{\mathrm{e}}\right]$, which is obviously to be phonemicized as /e/ (in parallel to the $\left[\mathrm{i}^{\mathrm{e}}\right.$ ] symbol used following palatalized consonants). In Modern Russian, the situation is more complex, in that /e/ and /o/ behave exactly like after palatalized consonants in reducing to /i/ (phonetically [i]), at least in those cases where there is evidence from alternations as to the nature of the stressed vowel. In the case of /e/ this is in any case the expected behaviour, as shown in Section I.I.I. This is demonstrated in (22) and (23) (see below for exceptions).

(22) (a) ['z $\left.{ }^{\mathrm{w} e m t}{ }^{\mathrm{j} j} \mathrm{j}\right] \quad$ 'pearl'

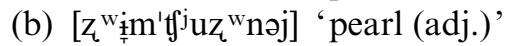

(23) (a) ['z ${ }^{\mathrm{w}}$ oni $]$ 'wives'

(b) [ $\left.\mathrm{z}_{\mathrm{T}}^{\mathrm{w}}{ }_{\mathrm{i}}^{\mathrm{\prime}} \mathrm{na}\right]$ 'wife'

[6] According to older descriptions of Russian phonology such as Avanesov (I956), if an inflectional suffix is to undergo radical reduction following a palatalized consonant, /a/ is realized as [ə], while /e/ and /o/ are realized as [i]. However, it remains unclear to what extent the data are reliable, especially in the case of early descriptions. In any case, the phenomenon was progressively on the wane during the 2oth century: see e.g. Bondarko \& Verbickaja (1973) for attrition of the system. Kniazev (2006) reports that his acoustic and perceptual experiments show complete neutralization for all vowels except $/ \mathrm{u} /$ in this context. Thus, it would seem that in the modern variety of Standard Russian the potentially problematic facts do not obtain, and I assume as much in this paper. 
As for $/ \mathrm{a} /$, there is considerable variation, the precise nature of which has remained largely unexplored. The consensus seems to be that there is variation across lexical items. What seems to be happening, in any case, is the progressive spread of the retention of $/ \mathrm{a} /$.

All sources agree that borrowings with unstressed /o/, even well-nativized ones, have /a/ as the outcome of reduction, as in (24).

(24) (a) ['s'ok] 'shock (n.)'

(b) $\left[\mathrm{S}^{\mathrm{w}} \mathrm{e}^{\mathrm{k}} \mathrm{k}\right.$ irəvəti $]$ 'shock (v.)'

Alternatively, borrowings may fail to undergo reduction at all (see below). As for /ts/, there are only very few words where it is followed by an unstressed $/ \mathrm{a} /$ or $/ \mathrm{o} /$, so generalizations are hard to come by; it does seem that $[\mathrm{p}]$ is taking over.

The overall picture is clear, even if not all details are sufficiently understood: the system is in transition from a state where there is a mismatch between the phonetic properties of the 'unpaired' non-palatalized consonants and their phonological behaviour to a state where their behaviour with respect to vowel reduction is more straightforwardly defined by their phonetic properties.

Finally, borrowings, especially those which are not well-nativized or belong to technical vocabulary, may fail to undergo vowel reduction in the relevant sense altogether. This means that vowels in these words retain their quality (e.g. labialization of $/ \mathrm{o} /$ ) even in unstressed syllables. They are still 'reduced' in the sense that they have a shorter duration under normal conditions.

(25) (a) [bŏ.'a] 'boa'

(b) [liě̀'gatŏ] 'legato'

\section{I.2 The facts, take two}

Before I turn to the technical analysis in Section 2, I present a body of data which have seldom been brought to bear on the issue of how Russian vowel reduction is to be described in phonological terms. Specifically, I provide evidence that only a small fraction of the data presented above are in fact directly relevant to a phonological analysis of vowel reduction in Russian. I propose, following Barnes $(2006,2007)$, that only the patterns of neutralization among the five vowels of Russian are explananda for phonological theory, while much of the detail is to be explained as a consequence of phonetic implementation.

\section{I.2.I Radical reduction is reduced duration}

In phonological accounts of Russian vowel reduction, especially in the generative tradition (see Section 3 below for an overview), it has been customary 
to analyse 'moderate' and 'radical' reduction as two phonological processes with outputs that are distinct units of the phonological alphabet. This is problematic for a variety of reasons, both conceptual and empirical.

On the conceptual side of things, the relatively fine-grained traditional approach distinguishes, for instance, [ə] and [ $[\mathrm{e}]$ (the latter often identified with [a]). Consequently, segments such as [ə], which are not used to implement lexical contrast in Modern Standard Russian, are admitted into the phonological alphabet. Therefore, an analysis of Russian vowel reduction which recognizes radical reduction as a separate phonetic process would appear to present a problem for contrastivist approaches which eschew redundant features in phonological computation (Dresher, Piggott \& Rice 1994, Morén 2003, Hall 2007, Dresher 2009).

The empirical difficulty can be summarized as follows: contexts for radical reduction are simultaneously contexts for extremely reduced duration, and contexts for moderate reduction are simultaneously contexts for less reduced duration. This opens up the possibility that the crucial difference between moderate and radical reduction is simply duration, not some phonological representation.

This position is most clearly stated by Barnes $(2006,2007)$. On the basis of experimental data, he demonstrates that the chief factor determining the FI value of the segment which represents the outcome of $/ \mathrm{o} /$ and $/ \mathrm{a} / \mathrm{neu}-$ tralization is actual duration, while position relative to the stressed syllable does not play a significant role. Specifically, if an unstressed syllable which is not in the first pretonic position is sufficiently lengthened (for whatever reason), the FI of the vowel can be as high as that of a vowel in the first pretonic syllable, or even in the stressed syllable. The same effect obtains in the first pretonic syllable: given sufficient length, the /o/-/a/ vowel in this position is qualitatively the same as stressed $/ \mathrm{a} / .^{7}$ Barnes concludes, correctly in my opinion, that a phonological distinction between [ə] and [e] and [a] is not a valid one: rather they represent a continuum of possible realizations of a single segment /a/ as constrained by the duration of the unstressed syllable. Thus, the role of position in the realization of unstressed vowels is indirect, insofar as position determines possible lengths.

This interpretation allows Barnes (2007) to provide a very straightforward explanation of the cases of 'moderate' reduction in 'exceptional' contexts. Recall that exceptional moderate reduction appears in onsetless syllables (consistently so in phrase-initial position). If moderate reduction is simply phonetic lengthening, it can be explained as an instance of the well-known

[7] Kniazev (2006: 47-50) presents similar results for a study of stressed and first-pretonicsyllable vowels in various prosodic positions (with and without phrasal pitch accent). $\mathrm{He}$ finds that the formant values and intensity for stressed and unstressed vowels are all but identical; in fact the only feature that reliably distinguishes between the two positions is length - but only under phrasal accent. 
phenomenon of lengthening at a domain boundary (Fougeron \& Keating 1997). Barnes (2007) also shows how lengthening in non-initial onsetless syllables and in hiatus can be explained. The gradient nature of exceptional moderate reduction in phrase-final open syllables also needs no additional explanation, since it is again found at a domain boundary. This particular case brings out an advantage of length-related interpretation: an account in terms of discrete phonological elements [ə] and [a] (and possibly [e]?) would need some special device to derive the gradient nature of this alternation in the phonology, whereas if it is a phonetic phenomenon, the variability is in fact to be expected.

Further evidence for this interpretation can be found in the sources. First, if reduction to [ə] and similar segments were phonological, we could expect significant phonetic stability, in that a phonological /a/ would provide a target for phonetic implementation (Keating 1988). This is manifestly not the case in Russian. Vowels in radical reduction positions (i.e. where they surface as [ə] and [i]]) are notoriously susceptible to coarticulation effects (Paufošima I980) or deletion. Thus, for example, '[ə]' is normally assimilated to the $/ \mathrm{u} / \mathrm{of}$ a following syllable, even if the latter is unstressed:

(26) (a) [pe.'uk] 'spider'

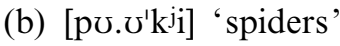

However, this process is clearly a gradient coarticulation phenomenon rather than a categorical phonological process, since unassimilated pronunciations are also possible and the conditioning factors are often speech rate and style. Thus, the supposed phonological / $/$ / is not in fact always phonetic [ə]. The reverse is also true. Consider the case of $/ u /$. It is normally assumed not to neutralize with any other segment, i.e. it 'does not reduce'. In fact, however, its phonetic realization varies very widely, from $[\mathrm{u}]$ to $[\mathrm{v}]$ and

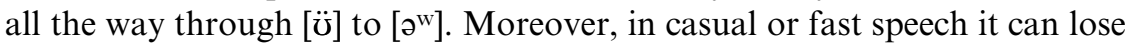
its labialization and neutralize with other vowels in a [ə]- or a [ï]-like sound (see e.g. Likhtman I999), yet it seems that this process does not represent true phonological vowel reduction, but is rather a phonetic phenomenon. What such facts show is that many cases of surface [ə] (or something like it) are not to be ascribed to a phonological $/ \mathrm{a} /$; it then follows that cases of putative phonological /a/ need positive evidence, which, as I show in this section, is hard to find.

There is even more evidence that the distinction between various reduction grades is mainly one of duration. Kasatkina (2005) notes that many published transcriptions of running speech have [ə] instead of [ $\mathrm{e}]$ in the first pretonic syllable, especially when the stressed vowel is [a]. While this system is reminiscent of (and obviously related to) the 'dissimilative akan'je' patterns (Crosswhite 2000, Bethin 2006), where such an alternation is clearly phonologized, it is nowhere near as regular in Standard Russian as spoken in Moscow. Kasatkina (2005) notes that there is a length trade-off between the 
stressed syllable and the first pretonic syllable, in that a lower (and thus inherently longer) stressed vowel may cause shortening of the first pretonic syllable. Thus, 'exceptional' radical reduction in the first pretonic syllable is merely the instantiation of reduced duration caused by this trade-off.

I conclude that an [ə] in transcription does not necessarily involve a phonological change to an /o/ segment, and thus that the non-peripheral vowels appearing as the outcome of vowel reduction are to be interpreted as artifacts of undershoot under conditions of reduced duration. ${ }^{8}$

One potential piece of counterevidence is mentioned by Kniazev \& Požarickaya (2005). They claim that in words with stress on the fifth syllable, the first syllable can be prolonged, but they transcribe it with the symbol for [ə], so $k r[ə x]$ snoproletárskij 'of the red proletariat'; under the interpretation proposed here the vowel in such a syllable should be more [a]-like. In the absence of actual phonetic data on the pronunciation of such words (which are relatively rare), I leave this question for further research. ${ }^{9}$

\section{I.2.2 Reduction is real}

The analysis in the previous section poses a serious question: if such a great deal of the vowel reduction facts is due to the phonetics of reduced duration, how do we know that the posited neutralization processes are in fact real and not artifacts of reduced duration too?

One reason why that is unlikely is the direction of neutralization: since /a/, the lower vowel, has longer intrinsic duration, it is not entirely clear how shortening could promote this sort of neutralization (though Padgett \& Tabain (2005) show how shortening promotes neutralization in general - by pushing vowels closer together, overstepping the perceptibility threshold). The question, however, remains: do we actually know that the phonological computation maps underlying /o/ to surface /a/ and underlying /e/ to surface /i/?

The principal evidence in this case comes from cases where duration is increased for one reason or another, but neutralization still happens. This may occur both under laboratory conditions and in actual speech.

[8] This section has concentrated on [ə] and [e], since the neutralization of $/ a /$ and $/ 0 /$ is the most widely studied phenomenon; data for other vowels are harder to come by (though see Kasatkina 2005, Kniazev 2006). In any case, reduction after palatalized consonants presents fewer compelling examples of a similar sort, since reduced duration leads to formant values of the vowel being largely obscured by the $\mathrm{F}_{2}$ transition associated with palatalized consonants, so reduction following such consonants is more consistently transcribed as [I] or [i], which have $\mathrm{F}_{2}$ values very close to that transition.

[9] This particular word is a compound, and in the base form krásnyj 'red' the vowel [a] is stressed; we thus expect secondary stress in kràsnoproletárskij, and Kasatkina (2005) claims that secondary stress is manifested by lack of reduction. I read this as implying that under secondary stress a more [a]-like vowel is expected, so the sources are in fact contradictory. 
A laboratory study was undertaken by Barnes (2007), who set up his experiment to promote hyperarticulation, essentially forcing the speakers to prolong all vowels, including unstressed ones. His results are unambiguous: while the difference between [a] and [ə] as the outcomes of reduction turns out to be illusory, duration does not influence the extent of neutralization of underlying $/ \mathrm{o} /$ and $/ \mathrm{a} /$ : for both of these segments in unstressed positions, the FI target is clearly that associated with stressed /a/, modulated by length restrictions. He notes that a high FI target for both of these segments is also consistent with the results of Padgett \& Tabain (2005), who themselves note that unstressed [a] (i.e. [e]) is lower than it would be expected to be if vowelspace cramping alone were responsible for reduction.

Lengthening (or at least lack of shortening) can also occur 'in the wild': as noted above, Kniazev (2006) finds that vowels in moderate reduction contexts (first pretonic syllable, onsetless syllable, phrase-final open syllable) can be as long as those in stressed syllables, and nevertheless neutralization is intact.

An important context for lengthening is the first pretonic syllable, which is consistently longer than other unstressed syllables. It is, however, not the case that it is always consistently shorter than the stressed syllable. In particular, it is lengthened in a number of intonational constructions, as demonstrated by Kasatkina (2005). Specifically, 'focused' words (in Moscow pronunciation) are often characterized by a rising pitch contour on the first pretonic syllable. It is well-known that rising pitch requires bigger excursions and thus can promote lengthening of the tone-bearing segments (e.g. Ohala I978). Kasatkina (2005) observes that pretonic vowels with rising pitch are lengthened, and sometimes even become longer than stressed vowels. ${ }^{10}$

Nevertheless, even under conditions of this lengthening, the neutralization happens, as in podx[a:]dit' 'approach (v.)' (Kasatkina 2005: 4I), compare podxód 'approach (n.)'.

In fact, the interaction of pitch and length also gives a clue to the special status of the first pretonic syllable. If lengthening in the first pretonic syllable is an artifact of the placement of tonal accents with respect to the stressed syllable, the 'bisyllabic domain' of Bethin (I998), consisting of the stressed and the first pretonic syllable, is reduced to a descriptive generalization, and is not necessarily a representational entity such as for example the foot, as in the analysis of Crosswhite (2000), on which see below. ${ }^{11}$

[Io] I thank Anton Zimmerling for drawing my attention to the potential role of pitch in lengthening. A very similar approach is taken by Bethin (2006).

[II] It does seem that lengthening of the first pretonic syllable is not necessarily contingent on pitch, and may be an independent phenomenon of the grammar. Kasatkina (2005) identifies a number of prosodic constructions where the first pretonic syllable is lengthened but does not receive rising pitch. Note that I am not claiming that lengthening is in fact a phonological reality rather than an aspect of language-specific phonetic implementation; one could speculate, for example, that lengthening could happen for functional reasons, to 
The independence of length-related facts and potential for $/ \mathrm{o} /-/ \mathrm{a} /$ neutralization is further confirmed by the behaviour of unassimilated loanwords. As noted above, vowels in such words can fail to undergo 'reduction', in that there are no changes in vowel quality even in unstressed syllables. Nevertheless, the duration of such unstressed syllables is still smaller than that of stressed syllables, which shows that shortening does not necessarily imply neutralization.

Summarizing this section, I have presented evidence for the following three claims:

- The distinction between 'radical' and 'moderate' reduction is an artifact of differences in duration, in that shorter syllables tend to be more strongly undershot, which produces an [ə] sound, while smaller undershoot permits the production of less centralized vowels.

- At the same time, I have proposed that length differences do not follow rigidly from the phonological structure, being contingent on factors such as speech rate and style, prosodic position, presence/absence of nuclear accent and pitch contours, etc.

- The phonological module is responsible for a number of symbolic operations, specifically the collapse of $/ \mathrm{o} /-/ \mathrm{a} /$ and $/ \mathrm{e} /-/ \mathrm{i} /$ distinctions (with the second member of both pairs as output) following non-palatalized consonants, and the neutralization of all vowels except $/ \mathrm{u} /$ following palatalized consonants.

In the next section I present a technical analysis of these phonological patterns. $^{12}$

increase the salience of contrasts potentially expressed by pitch movement on the first pretonic syllable.

[12] A $J L$ referee asks whether the conception of the phonetics-phonology interface I espouse is applicable to the case of the [i] segment, in that it would be expected that under certain conditions (such as hyperarticulation) the '[i]' is expected to reach the formant values of [i]. This prediction is somewhat borne out by the data: for instance, Bondarko (1977: 38, 64) states explicitly that the acoustic characteristics of the final portion of [i] are very similar to those of [i]. However, both Keating (1987, I996) and Padgett (200I) found that, despite significant overlap, the $\mathrm{F}_{2}$ values of [i] following palatalized and non-palatalized consonants are indeed different. Nevertheless, they both suggest that this can be accounted for in terms of a richer theory of the phonology-phonetics interface, such as Keating's (I990a) window model of coarticulation. Specifically, this model allows for the window of the realizations of a single phonological segment to be adjusted depending on the phonetic context without implying a phonological change, which means that the difference between the windows for [i] following palatalized and non-palatalized consonants need not be taken as evidence for a distinction between phonological /i/ and /it/. This conclusion is further buttressed by the fact that Keating $(1987$, 1996) found a similar effect for /a/, for which the absence of a [back] contrast in Russian is uncontroversial. Thus, I assume that both [a] and [i] are not phonological segments, but the mechanism for their appearance is subtly different: reduced duration without any significant adjustment of the window in the former case and window alteration in the latter. 


\section{ANALYSIS}

In this section I present an analysis of Russian vowel reduction in terms of the Parallel Structures Model of feature geometry (Morén 2003, 2006). I show how a language-specific approach to phonological representations leads to a simple analysis of vowel reduction in Russian without recourse to sonorityspecific constraints.

\section{I The model}

In the Parallel Structures Model of feature geometry (henceforth PSM), the phonological make-up of segments is determined on the basis of their phonological activity in the particular language under consideration. This means that, modulo other assumptions, a segment is specified for a feature $[\mathrm{F}]$ only if reference to $[\mathrm{F}]$ is crucially necessary to describe some phonological phenomenon (i.e. lexical contrast or alternations). In this sense, the PSM approach is related to the theory of contrast espoused by Dresher et al. (1994), Hall (2007), Dresher (2009). ${ }^{13}$

The workings of the Parallel Structures Model are as follows. First, PSM utilizes a rich feature geometry with head and dependent nodes for each dimension (Place, Manner, Laryngeal, etc.). In the spirit of Clements (I99I) and Clements \& Hume (I995), head nodes are referred to as $\mathrm{C}$-\{Place,Manner,...\}, and dependent nodes are referred to as V-nodes. However, in PSM this is a purely notational convention without any intrinsic content: consonants can have V-features (e.g. this is the case for palatalized consonants in Russian), and vowels can potentially have Cfeatures.

Second, there are no major class features such as [vocalic] or [consonantal]. Major classes are identified as stricture classes, and are represented using manner features (at least [open] and [closed]), see Steriade (1993).

Third, features are assumed to be uniformly privative, much as in e.g. Dependency Phonology (Anderson \& Ewen 1987) or Element Theory (Harris \& Lindsey 1995). In practice, this means that $[-\mathrm{F}]$ cannot be used either in the representations or in the constraints.

\subsection{Representation of the vowels}

In this subsection I introduce the representations to be used in this paper, and propose an account of the Russian vowel inventory in terms of Optimality Theory (henceforth OT).

[13] See also Dresher (2009) for discussion of the structuralist precursors of this approach, starting from Trubetzkoy (I939). 


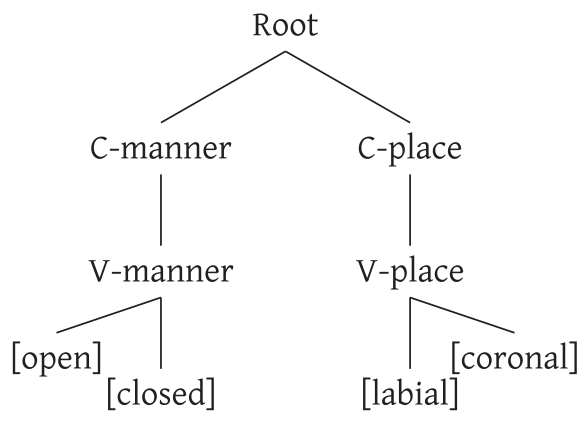

Figure 4

Feature geometry for Russian vowels.

\subsection{Feature specifications}

Figure 4 shows the feature geometry I propose for Russian vowels. It makes use of the place features [labial] and [coronal], which can potentially be used for round and front vowels respectively, and the manner features [open] and [closed], with the former implying (relative) lowness and the latter (relative) highness. However, the assignment of these features is nontrivial.

First, since all features are privative, there is no obvious way of referring to classes such as [- high] or [-round], which play an important role in other analyses of the phenomena.

Second, the PSM is predicated on the assumption that feature assignment reflects phonological activity. Thus, the four features proposed must be distributed in the inventory in such a way that they reflect the patterns of reduction. ${ }^{14}$

The feature assignment I propose for Modern Russian is demonstrated in Table 2. The most important facts to note about the hypothesis are as follows:

- There is no coherent class of [+ high] vowels, which, as we shall see below, plays an important role in some sonority-based analyses of the Russian phenomena.

- Since only phonologically significant features come into play, a phonetic property can be phonologically relevant for some segments but not for others. This is the case with roundness, expressed here as V-place[labial]: the phonetically rounded /o/ does not bear the feature. This is so because

[14] Given the rich literature on Russian palatalization, often argued to spread to preceding consonants from following front vowels, one might potentially want to include the palatalization facts into consideration when deciding on featural representations for vowels. This is taken into account in the present system, where both /i/ and /e/ have the palatalization-ensuring feature V-place[coronal]. For explicit discussion, see Iosad \& Morén-Duolljá (2012). 


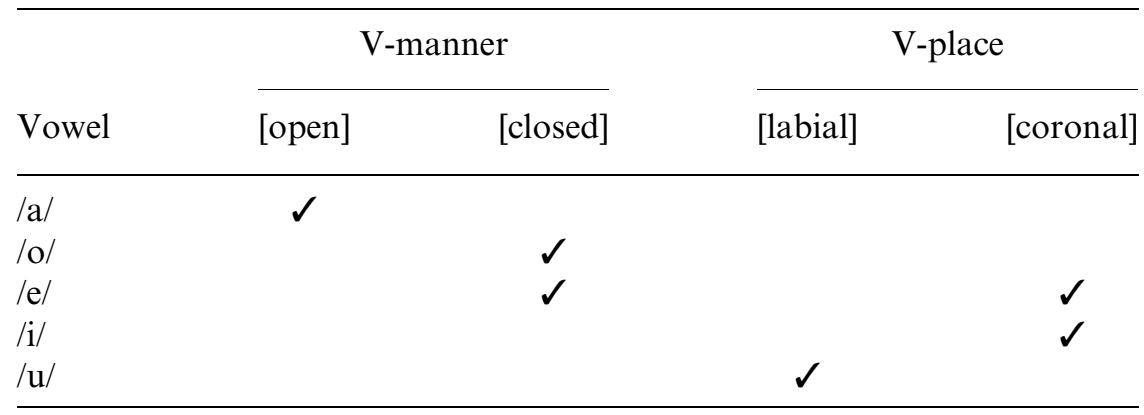

Table 2

Feature specifications for Russian vowels.

the rounded vowels $/ \mathrm{o} /$ and $/ \mathrm{u} /$ nowhere pattern together, and $/ \mathrm{o} /$ in fact shows no evidence of having any sort of roundedness feature.

- The representation of mid vowels is asymmetrical. One alternative here would be a system similar to a Dependency Phonology analysis (Hermans 2008) or one based on elements (see in particular Harris 2005), with V-place features corresponding to the $\{\mathrm{I}\}$ and $\{\mathrm{U}\}$ elements and $\mathrm{V}$-manner[open] to the $\{\mathrm{A}\}$ element. However, symmetrical representations for mid vowels present insurmountable problems with faithfulness, as I demonstrate below (Section 3.5).

If these representations are accepted, vowel reduction following nonpalatalized consonants is quite straightforwardly represented as deletion of the feature V-manner[closed], which leads to a reduction in phonological complexity (see Harris $(1997,2005)$ for a forceful argument for reduction as a complexity-related phenomenon in privative-feature theories). No recourse is made to factors such as e.g. perceptual (non-)salience (Crosswhite 2000, Padgett \& Tabain 2005) or sonority (de Lacy 2006, Hermans 2008); since this is a straightforward markedness-based explanation, and featural markedness constraints of the form $*[\mathrm{~F}]$ are independently needed, such an account is more parsimonious, at least as far as purely phonological considerations go.

The representational proposal made in this section is essentially theoryagnostic: it can be adapted to any number of theories of phonological computation. In this paper, however, I present an analysis in terms of OT. In Sections 2.2.2 and 2.3 I discuss the constraints and rankings operative on Russian vowels.

\subsubsection{Constraints and rankings for stressed vowels}

Before providing an account of vowel reduction, I will demonstrate how the representations in Table 2 can be derived for stressed vowels. This is necessary if one assumes Richness of the Base, to make sure that potentially 
illicit inputs do not surface unchanged; for another example of this procedure, see Morén (2006). ${ }^{15}$

Since (most) underlying vowels only surface faithfully in stressed positions, we need to assume some computational device to make sure that stressed and unstressed positions are treated differently. In this paper I assume that this effect is due to positional faithfulness constraints applying to prosodic heads (Beckman 1999, Alderete 1999). ${ }^{16}$

In line with Morén (2006), I assume that the Generator function of OT only outputs potentially licit PSM representations, i.e. that, say, it does not provide the evaluation with structures where a V-node dominates a $\mathrm{C}$-node or where a feature is attached directly to the root node. However, the evaluation component still has a role to play, as it filters out structures which are disallowed in the particular language.

Assuming a Correspondence theory of faithfulness, I employ two types of constraints:

- $\operatorname{Max}([\mathrm{F}])$ constraints, prohibiting deletion. In the framework employed here, $[\mathrm{F}]$ can stand for a feature attached to a specific class node.

- *[F] constraints (with the same understanding of [F]) militate against certain features appearing in the surface representations. Following Morén (2006), I also assume that markedness constraints can be locally conjoined, militating against segments which contain features banned by both of the conjoined constraints. I refer to Morén (2006) for discussion of multiple constraint conjunction. ${ }^{17}$

The existence of a contrast is accounted for by the standard OT ranking of faithfulness above markedness. Thus, the representation $\{\mathrm{V}$-place[labial]\} surfaces faithfully because $\mathrm{MAx}(\mathrm{V}$-place[labial]) is ranked above $* \mathrm{~V}$-place [labial], as shown in (27). The same ranking obtains for V-place[coronal] and $\mathrm{V}$-manner[open], since these also surface faithfully, as /i/ and /a/ respectively.

[15] Morén (2007) entertains the possibility that once the licit representations of a given language are in place (presumably once the acquisition process is complete), the Generator function does not submit impossible representations for evaluation. If this point of view is accepted, the following discussion is of course unnecessary.

[I6] The Russian vowel reduction data appear to be equally compatible with a positional markedness or positional licensing approach (e.g. Zoll I998b, Walker 2005). I use positional faithfulness throughout for concreteness.

[17] An anonymous $J L$ referee asks whether the use of local conjunction may lead to undesirable factorial consequences (see Potts et al. 20I0). However, I believe that this is a relatively benign type of local conjunction, since it is used to formalize feature co-occurrence restrictions. Some sort of constraint schema militating against the co-occurrence of features is unavoidable in OT, especially with Richness of the Base, to express language-particular restrictions on inventories; if local conjunction is ultimately found unsuitable for this purpose, the analysis can certainly be adapted to whatever mechanism one chooses, see also Morén (2007). See also Section 3.6 below for discussion of the importance of factorialtypology arguments. 
(27) Surfacing of V-place[labial]

\begin{tabular}{|cc|c|c|}
\hline$\{\mathrm{V}-\mathrm{pl}[\mathrm{lab}]\}$ & $/ \mathrm{u} /$ & $\mathrm{MAX}_{\mathrm{Hd}}(\mathrm{V}-\mathrm{pl}[\mathrm{lab}]$ & $* \mathrm{~V}-\mathrm{pl}[\mathrm{lab}]$ \\
\hline a. $\{\mathrm{V}-\mathrm{pl}[\mathrm{lab}]\} / \mathrm{u} /$ & & $*$ \\
\hline b. \{\} & $/ /$ & $* !$ & \\
\hline
\end{tabular}

On the other hand, a potential input consisting of a feature that cannot make up a segment on its own does not surface faithfully because the reverse ranking obtains for this feature. For instance, Russian does not makes use of the feature $\mathrm{V}$-place[dorsal], which is explained by the following ranking:

(28) Potential V-place[dor] cannot surface

\begin{tabular}{|cc|c|c|}
\hline$\{\mathrm{V}$-pl[dor] & $/ ? ? /$ & $* \mathrm{~V}$-pl[dor] & $\mathrm{MAX}_{\mathrm{Hd}}(\mathrm{V}-\mathrm{pl}[\mathrm{dor}]$ \\
\hline a. $\{\mathrm{V}$-pl[dor] $\}$ & $/ ? ? /$ & $* !$ & \\
\hline b. \{\} & $/ /$ & & $*$ \\
\hline
\end{tabular}

When the input consists of more than one feature, conjoined constraints potentially come into play. Thus, when a combination of two features surfaces faithfully, this means that $\mathrm{MAX}_{\mathrm{Hd}}$ constraints for both features outrank the conjoined constraint against that combination of features. This is shown in (29) for the vowel /e/.

(29) $\{$ V-place[coronal],V-manner[closed] $\}$ surfaces faithfully

\begin{tabular}{|rr|c:c|c|}
\hline$\{\mathrm{V}-\mathrm{pl}[\mathrm{cor}], \mathrm{V}-\mathrm{man}[\mathrm{cl}]\}$ & $/ \mathrm{e} /$ & $\begin{array}{c}\mathrm{MAX}_{\mathrm{Hd}} \\
(\mathrm{V}-\mathrm{pl}[\mathrm{cor}])\end{array}$ & $\begin{array}{c}\mathrm{MAX}_{\mathrm{Hd}} \\
(\mathrm{V}-\mathrm{man}[\mathrm{cl}])\end{array}$ & $* \mathrm{~V}$-pl[cor]\&*V-man[cl] \\
\hline a. $\{\mathrm{V}-\mathrm{pl}[\mathrm{cor}], \mathrm{V}-\mathrm{man}[\mathrm{cl}]\}$ & $/ \mathrm{e} /$ & & & $*$ \\
\hline b. $\{\mathrm{V}-\mathrm{pl}[\mathrm{cor}]\}$ & $/ \mathrm{i} /$ & & $* !$ & \\
\hline c. $\{\mathrm{V}-\mathrm{man}[\mathrm{cl}]\}$ & $/ \mathrm{o} /$ & $* !$ & & \\
\hline d. \{\} & $/ /$ & $* !$ & $*$ & \\
\hline
\end{tabular}

Illicit combinations of features, on the other hand, cannot surface because the conjoined markedness constraint dominates one or more of the faithfulness constraints. This is exemplified by (30), which shows why the impossible combination $\{\mathrm{V}$-manner[closed], V-manner[open]\} cannot surface faithfully, even though it could be a reasonable representation for $/ \mathrm{o} /$. The actual winner depends on the ranking between the two faithfulness constraints, but I am not aware of any evidence from Russian which would provide evidence on this point, so I leave the matter undecided. 
(30) $\{\mathrm{V}$-manner[open],V-manner[closed] $\}$ is illicit

\begin{tabular}{|c|c|c|c|c|}
\hline$\{\mathrm{V}-\mathrm{man}[\mathrm{op}], \mathrm{V}-\mathrm{man}[\mathrm{cl}]\}$ & /??/ & $\begin{array}{l}* \mathrm{~V}-\operatorname{man}[\mathrm{op}] \& \\
* \mathrm{~V}-\mathrm{man}[\mathrm{cl}]\end{array}$ & $\begin{array}{c}\mathrm{MAX}_{\mathrm{Hd}} \\
(\mathrm{V}-\mathrm{man}[\mathrm{op}])\end{array}$ & $\operatorname{MAX}_{\mathrm{Hd}}(\mathrm{V}-\mathrm{man}[\mathrm{cl}])$ \\
\hline a. $\{\mathrm{V}-\mathrm{man}[\mathrm{op}], \mathrm{V}-\mathrm{man}[\mathrm{cl}]\}$ & $/ ? ? /$ & $* !$ & & \\
\hline$\leftarrow$ b. $\{\mathrm{V}-\mathrm{man}[\mathrm{op}]\}$ & /a/ & & & $*$ \\
\hline$\leftrightarrow$ c. $\{\mathrm{V}-\mathrm{man}[\mathrm{cl}]\}$ & $/ 0 /$ & & $*$ & \\
\hline
\end{tabular}

The same effect is achieved if the conjoined markedness constraint dominates only one faithfulness constraint, as shown in (3I).

(3I) $\{\mathrm{V}$-manner[open],V-manner[closed] $\}$ is illicit (a different ranking)

\begin{tabular}{|cc|c:c|c|}
\hline$\{\mathrm{V}-\mathrm{man}[\mathrm{op}], \mathrm{V}-\mathrm{man}[\mathrm{cl}]\}$ & $/ ? ? /$ & $\begin{array}{c}\mathrm{MAX}_{\mathrm{Hd}} \\
(\mathrm{V}-\operatorname{man}[\mathrm{op}])\end{array}$ & $\begin{array}{c}* \mathrm{~V}-\operatorname{man}[\mathrm{op}] \&-\mathrm{Man}[\mathrm{cl}] \\
*\end{array}$ & $\mathrm{MAX}_{\mathrm{Hd}}(\mathrm{V}-\mathrm{man}[\mathrm{cl}])$ \\
\hline a. $\{\mathrm{V}-\mathrm{man}[\mathrm{op}], \mathrm{V}-\operatorname{man}[\mathrm{cl}]\}$ & $/ ? ? /$ & & $* !$ & $*$ \\
\hline b. $\{\mathrm{V}-\mathrm{man}[\mathrm{op}]\}$ & $/ \mathrm{a} /$ & & & \\
\hline c. $\{\mathrm{V}-\mathrm{man}[\mathrm{cl}]\}$ & $/ \mathrm{o} /$ & $* !$ & & \\
\hline
\end{tabular}

With respect to potential three-feature inputs, no Russian vowel surfaces with three features. I am also not aware of any processes which might give insights as to how such illicit inputs are repaired. In any case, this restriction can be derived in the same way as the restriction on illicit two-feature structures: the conjoined markedness constraint dominates at least one faithfulness constraint, as shown in $(32) .{ }^{18}$ For reasons of space, candidates with fewer than three features which are otherwise not licit segments (such as $\{\mathrm{V}$-manner[open],V-place[coronal]\}) are excluded.

(32) $\{\mathrm{V}$-place[coronal],V-manner[open], V-manner[closed]\} is illicit

\begin{tabular}{|c|c|c|c|c|c|}
\hline $\begin{array}{l}\{\mathrm{V}-\mathrm{pl}[\mathrm{cor}], \mathrm{V}-\mathrm{man}[\mathrm{op}] \\
\mathrm{V}-\mathrm{man}[\mathrm{cl}]\}\end{array}$ & $/ ? ? /$ & $\begin{array}{c}\text { MAX }_{\mathrm{Hd}} \\
(\mathrm{V}-\mathrm{pl}[\mathrm{cor}])\end{array}$ & $\begin{array}{c}\operatorname{MAX}_{\mathrm{Hd}} \\
(\mathrm{V}-\mathrm{man}[\mathrm{cl}])\end{array}$ & $\begin{array}{c}* \mathrm{~V}-\mathrm{p} 1[\mathrm{cor} \& \\
* \mathrm{~V}-\mathrm{man}[\mathrm{op}] \& \\
* \mathrm{~V}-\mathrm{man}[\mathrm{cl}]\end{array}$ & $\begin{array}{c}\text { MAX }_{\mathrm{Hd}} \\
(\mathrm{V}-\mathrm{man}[\mathrm{op}])\end{array}$ \\
\hline $\begin{array}{l}\text { a. }\{\mathrm{V}-\mathrm{pl}[\mathrm{cor}] \\
\mathrm{V}-\mathrm{man}[\mathrm{op}] \\
\mathrm{V}-\mathrm{man}[\mathrm{cl}]\}\end{array}$ & $/ ? ? /$ & & & $* !$ & \\
\hline $\begin{aligned} \quad \text { b. } & \{\mathrm{V}-\mathrm{pl}[\mathrm{cor}], \\
& \mathrm{V}-\mathrm{man}[\mathrm{cl}]\}\end{aligned}$ & /e/ & & & & $*$ \\
\hline c. $\{\mathrm{V}-\mathrm{pl}[\mathrm{cor}]\}$ & $/ \mathrm{i} /$ & & $* !$ & & $*$ \\
\hline d. $\quad\{\mathrm{V}-\operatorname{man}[\mathrm{cl}]\}$ & $10 /$ & $* !$ & & & $*$ \\
\hline e. $\{\mathrm{V}-\operatorname{man}[\mathrm{op}]\}$ & $/ \mathrm{a} /$ & $*$ & $* !$ & & \\
\hline
\end{tabular}

[I8] I am not claiming that this is the actual ranking in Russian, since there is, as far as I know, no particular evidence for this input $\rightarrow$ output mapping. The tableau in (32) is purely illustrative. 
This concludes the demonstration of how the stressed vowel inventory of Russian can be derived using relatively simple faithfulness and markedness constraints. In the following sections I take up the analysis of vowels in unstressed syllables.

\subsection{Russian vowel reduction: The simple case}

First we turn to the simpler case of reduction, namely one where the vowel is preceded by a non-palatalized consonant. We assume that phonologically non-palatalized consonants (i.e. all those that are not phonetically palatalized minus $\left[\mathrm{s}^{\mathrm{w}}\right],\left[\mathrm{z}^{\mathrm{w}}\right]$, and [ts]) do not bear any secondary articulation feature. This position stands in contradistinction to both the traditional account, where such consonants are usually assumed to have (redundant) [-back] specifications, and to the position of Padgett (2003), who argues that velarization before [i] is phonologically relevant, since it participates in the expression of contrast (and presumably because a contrast between plain and velarized consonants is available in Universal Grammar, since other languages make use of it). I assume, following both contrastivist thinking in early structuralism and approaches such as those of Morén (2003), Blaho (2008), Dresher (2009), that only phonological activity within a language is to be reflected in the featural specifications. Thus, there are no redundant specifications, and, since there is no phonological contrast between [Cri] and [Ci] in Russian, I propose that there is no need to specify velarization or lack of palatalization in the phonology.

Thus, I assume that non-palatalized consonants (with some exceptions to be discussed below) do not bear vowel place features, and thus cannot intrude onto the reduction processes. Therefore, reduction in this context presents a kind of emergence of the unmarked effect, since potentially highranking constraints relevant to reduction following palatalized consonants are inactive, as their activity is presumably contingent on the presence of the palatalization feature.

The analysis of vowel reduction brings out an important advantage of the representations shown in Table 2. Specifically, if we assume that reduction is due to a prohibition on V-manner[closed] in prosodically weak positions, deletion of this feature leads to the desired result in one case of reduction.

Since the feature V-manner[closed] is only present in the mid vowels, the effect of a constraint against this feature is the same as that of a descriptive constraint *MID, as used by Alderete (I999), for example. More formally, this prohibition could be expressed as a feature co-occurrence constraint $*[-$ high - low $],{ }^{19}$ but this option is not available in a model with privative features.

[I9] Perhaps more accurately, as a local conjunction constraint $\left[*[- \text { high }] \&^{*}[- \text { low }]\right]_{\text {Seg }}$, or an implication constraint $*[-$ high $] /[-$ low $]$. 
Since the high vowels $/ \mathrm{i} /$ and $/ \mathrm{u} /$ and the low vowel /a/ do not possess the feature V-manner[closed], they satisfy the markedness constraint in all prosodic positions and are not expected to undergo reduction. This, as we have seen, is exactly the case, modulo the centralization phenomena which have been interpreted above as phonetic coarticulation facts. This is demonstrated for $/ \mathrm{u} /$ in (33). The constraint $\mathrm{MAX}_{\mathrm{Hd}}(\mathrm{V}$-place[labial]) is inactive, as it is vacuously satisfied in a non-head context.

(33) No reduction of $/ \mathrm{u} /$

\begin{tabular}{|lr|c:c|c|}
\hline $\mathrm{t}\{\mathrm{V}-\mathrm{pl}[\mathrm{lab}]\}$ & $/ \mathrm{tu} /$ & $\begin{array}{c}\mathrm{MAX}_{\mathrm{Hd}} \\
(\mathrm{V}-\mathrm{pl}[\mathrm{lab}])\end{array}$ & $\mathrm{MAX}(\mathrm{V}-\mathrm{pl}[\mathrm{lab}])$ & $* \mathrm{~V}-\mathrm{pl}[\mathrm{lab}]$ \\
\hline a. $\{\mathrm{V}-\mathrm{man}[\mathrm{op}], \mathrm{V}-\mathrm{man}[\mathrm{cl}]\}$ & $/ \mathrm{tu} /$ & & & $*$ \\
\hline b. $\mathrm{t}\{\}$ & $/ \mathrm{t} ? /$ & & $* !$ & \\
\hline
\end{tabular}

The mid vowel /e/ is subject to the classic positional faithfulness ranking, which leads to deletion of the offending feature in non-head position. Given the representations in Table 2 , this deletion creates $/ \mathrm{i} /$, which is exactly the outcome of the reduction of this vowel in Modern Standard Russian. This is demonstrated in example (34).

(34) Reduction of /Ce/

\begin{tabular}{|cc|c|c|c|}
\hline $\mathrm{t}\{\mathrm{V}-\mathrm{man}[\mathrm{cl}], \mathrm{V}-\mathrm{pl}[\mathrm{cor}]\}$ & $/ \mathrm{te} /$ & $\begin{array}{c}\mathrm{MAX}_{\mathrm{Hd}} \\
(\mathrm{V}-\mathrm{man}[\mathrm{cl}])\end{array}$ & $* \mathrm{~V}-\mathrm{man}[\mathrm{cl}]$ & $\mathrm{MAx}(\mathrm{V}-\mathrm{man}[\mathrm{cl}])$ \\
\hline a. $\{\mathrm{V}-\mathrm{man}[\mathrm{cl}], \mathrm{V}-\mathrm{pl}[\mathrm{cor}]\}$ & $/ \mathrm{te} /$ & & $* !$ & \\
\hline b. $\mathrm{t}\{\mathrm{V}-\mathrm{pl}[\mathrm{cor}]\}$ & $/ \mathrm{ti} /$ & & & $*$ \\
\hline
\end{tabular}

The reduction of $/ \mathrm{o} /$ is a bit more complicated. The deletion of V-manner[closed] in this case would be expected to create the empty root node, which is not a licit representation in Modern Russian phonology. I propose that the non-appearance of an empty node is due to an augmentation constraint HaVEMANNER, penalizing segments which do not bear a manner feature. Ranking this constraint above DeP(V-manner[open]) explains the pattern. ${ }^{20}$

(35) Reduction of $/ \mathrm{Co} /$

\begin{tabular}{|cc|c:c|c:c|}
\hline $\mathrm{t}\{\mathrm{V}-\mathrm{man}[\mathrm{cl}]\}$ & $/ \mathrm{to} /$ & HAVEMANNER & $* \mathrm{~V}-\operatorname{man}[\mathrm{cl}]$ & $\mathrm{MAX}(\mathrm{V}-\mathrm{man}[\mathrm{cl}])$ & $\operatorname{DEP}(\mathrm{V}-\mathrm{man}[\mathrm{op}])$ \\
\hline a. $\mathrm{t}\{\mathrm{V}-\mathrm{man}[\mathrm{cl}]\}$ & $/ \mathrm{to} /$ & & $* !$ & & \\
\hline b. $\mathrm{t}\{\mathrm{V}-\mathrm{man}[\mathrm{op}]\}$ & $/ \mathrm{ta} /$ & & & $*$ & $*$ \\
\hline c. $\mathrm{t}\{\}$ & $/ \mathrm{t} ? /$ & $* !$ & & $*$ & \\
\hline
\end{tabular}

The introduction of HaveMANNER raises the issue of why the mannerless vowels $/ \mathrm{i} /$ and $/ \mathrm{u} /$ can surface at all, both in stressed and unstressed positions.

[20] The constraint HaveManner is analogous to HavePlace, used by e.g. McCarthy (2008). 
In the case of $/ \mathrm{u} /$, the answer is simple: since $\mathrm{V}$-place[lab] does not combine with any other features, HAVEMANNER is ranked below the feature cooccurrence constraints. In the case of /i/, V-manner[open] cannot be epenthesized as in (35), again because of the feature co-occurrence restrictions. However, V-place[coronal] can combine with V-manner[closed] to form /e/. That this does not happen is explained by ranking $\operatorname{DEp}(\mathrm{V}-\operatorname{man}[\mathrm{cl}])$ above HaveManner, as shown in (36).

(36) Failure of manner epenthesis in /i/

\begin{tabular}{|cc|c|c|}
\hline$\{\mathrm{V}-\mathrm{pl}[\mathrm{cor}]\}$ & $/ \mathrm{i} /$ & $\mathrm{DEP}(\mathrm{V}-\operatorname{man}[\mathrm{cl}])$ & HAVEMANNER \\
\hline a. $\{\mathrm{V}-\mathrm{pl}[\mathrm{cor}]\}$ & $/ \mathrm{i} /$ & & $*$ \\
\hline b. $\{\mathrm{V}-\mathrm{pl}[\mathrm{cor}], \mathrm{V}-\operatorname{man}[\mathrm{cl}]\}$ & $/ \mathrm{e} /$ & $* !$ & \\
\hline
\end{tabular}

Thus, a simple constraint system is enough to produce a system where all vowels making up the inventory are realized in stressed positions, while in unstressed positions only those segments which consist of a single feature are allowed. Note that the representational system allows to capture the correct input-output mappings as well. In the next section I discuss the analysis of reduction following palatalized consonants.

\subsection{Russian vowel reduction: The complex case}

As we have seen above, the main difference between positions following a nonpalatalized and a palatalized consonant is that the latter disallows all nonhigh vowels. The outcome of reduction of all vowels except $/ u /$ is the vowel $/ \mathrm{i} /$.

To explain the pattern, we can leverage a key insight of Unified Feature Theory (Clements I99I, Clements \& Hume 1995) and note that the secondary articulation of palatalization is (potentially) represented by the same feature V-place[coronal] as the vowel /i/. That is, the majority of the vowels following consonants bearing a V-place[coronal] feature, map precisely to V-place[coronal]. I propose that this is not a coincidence, but rather an inevitable consequence of segmental organization, specifically, that reduction to $/ \mathrm{i} /$ is an instance of autosegmental spreading.

A full discussion of options to formulate constraints which promote spreading cannot be undertaken here. For the sake of the argument, I use the constraint SHARE(V-place[coronal]) (Honeybone 2006, McCarthy 2009). With respect to Russian, several caveats must be made, since spreading of V-place[coronal] might potentially affect other areas of the grammar which have nothing to do with vowel reduction and are thus outside the scope of this paper. For reasons of space and focus, I do not pursue an account of other processes which implicate the spreading of V-place[coronal] in Russian. ${ }^{21}$

[2I] For vowel-to-consonant spreading (or lack thereof), see Rubach (2000), Padgett (20II), Iosad \& Morén-Duolljá (2012). For consonant assimilation, see Zubritskaya (I997). The 
In stressed syllables, spreading is precluded by a positional faithfulness constraint DePLinK ${ }_{\mathrm{Hd}}(\mathrm{V}$-pl[coronal]), which prohibits the insertion of non-underlying associations of a root node and V-place[coronal], only in the head of the prosodic word. It only has to dominate SHARE, as shown in $(37)^{22}$

\section{(37) No spreading of V-place[coronal] into stressed syllables}

\begin{tabular}{|c|c|c|c|c|c|c|}
\hline \multicolumn{3}{|c|}{$\mathrm{t}^{\mathrm{j} 1}\{\mathrm{~V}-\mathrm{man}[\mathrm{cl}]\}$} & \multirow{2}{*}{\begin{tabular}{|l|}
$/ \mathrm{t}^{\mathrm{j}} \mathrm{o} /$ \\
$/ \mathrm{t}^{\mathrm{j}} \mathrm{o} /$
\end{tabular}} & \multirow{2}{*}{$\begin{array}{l}\text { DEPLINK }_{\mathrm{Hd}} \\
\text { (V-pl[cor]) }\end{array}$} & \multirow{2}{*}{$\begin{array}{c}\operatorname{MAX}_{\mathrm{Hd}} \\
(\mathrm{V}-\operatorname{man}[\mathrm{cl}])\end{array}$} & \multirow{2}{*}{$\begin{array}{c}\text { ShARE(V-pl[cor]) } \\
*\end{array}$} \\
\hline$\sigma$ & a. & $\mathrm{I}^{\mathrm{j}}{ }^{1}\{\mathrm{~V}-\mathrm{man}[\mathrm{cl}]\}$ & & & & \\
\hline & b. & $\mathrm{I}_{\mathrm{t}} \mathrm{j}^{1}\left\{\mathrm{~V}-\mathrm{pl}[\mathrm{cor}]_{1}\right\}$ & $/ \mathrm{t}_{\mathrm{i}} /$ & $*$ & $* !$ & \\
\hline & c. & $\mathrm{I}^{\mathrm{j}} \mathrm{t}^{1}\left\{\mathrm{~V}-\mathrm{pl}[\mathrm{cor}]_{1},(\mathrm{~V}-\mathrm{man}[\mathrm{cl}]\}\right.$ & $/ \mathrm{t}^{\mathrm{j}} \mathrm{e} /$ & $* !$ & & \\
\hline
\end{tabular}

In unstressed syllables, however, $\operatorname{SHARE}(\mathrm{V}$-place[coronal]) dominates both featural faithfulness and DepLink. In the case of /a/, this spreading leads to deletion of the existing feature, since the result would be an otherwise illicit segment, as shown in $(38){ }^{23}$

case of consonant assimilation is particularly problematic, since the data, as documented inter alia by Zubritskaya (1997), exhibit a great deal of variation. It also raises numerous representational issues. For instance, many consonant sequences only contrast in the palatalization of the final consonant (so there is a contrast between [tr] and [tri] but not between $[\operatorname{tr}]$ and $\left[\mathrm{tir}_{\mathrm{r}}\right]$ ) and it is not obvious that such sequences could not be represented with the palatalization feature being associated to the entire sequence. Such an assumption could introduce a mismatch between phonetics and phonology that requires more analysis than could be provided here. Interestingly, there is evidence from some dialects that such a mismatch is indeed possible at least in principle: in systems with so-called 'moderate $j a$ kan'je' non-high vowels are realized as [a] in the context $\mathrm{C}_{-} \mathrm{C}_{\mathrm{C}}$ and as [i] in the context $\mathrm{Cj}_{-} \mathrm{C}^{\mathrm{j}}$. However, in the case of consonant sequences some phonetically non-palatalized consonants act as if they were palatalized for the purposes of this rule if they precede a palatalized consonant, leading to alternations such as [sia'stra] 'sister (nom.sg.)' vs. [s'ij'strije] 'sister (dat.sg.)', which could be explained by assuming that the domain of the V-place[coronal] feature is the entire consonant sequence. These issues clearly need further research. In Section 3.I I also discuss an alternative approach which can be used if the spreading account ultimately fails.

[22] Example (37) shows the only case where $\operatorname{DEPLINK}_{\mathrm{Hd}}(\mathrm{V}$-place[coronal]) is truly necessary. In the case of $/ \mathrm{i} /$ and $/ \mathrm{e} /$, spreading does not make any phonetic difference, while for $/ \mathrm{a} / \mathrm{and} / \mathrm{u} /$ it would be excluded by feature co-occurrence restrictions. Only in the case of /o/ could it create a licit segment: the fact that it does not shows the necessity of the DepLinK constraint. For the Dep/MaxLinK constraint family, see Morén (200I). An anonymous referee expresses a concern with respect to the consequences of such a constraint for factorial typology. It appears that the most important non-trivial prediction made by the existence of a positional version of DePLink is the possibility of head elements being blockers of spreading, and this is exactly the pattern I suggest is attested in Russian.

[23] The relevant constraints are of course ranked below $\mathrm{MAx}_{\mathrm{Hd}}(\mathrm{V}-\mathrm{man}[\mathrm{op}])$. The ranking ensuring the lack of V-manner[closed] epenthesis is also omitted. 
(38) Reduction of $/ \mathrm{t}^{\mathrm{j}} \mathrm{a} /$

\begin{tabular}{|c|c|c|c|c|}
\hline $\mathrm{t}^{\mathrm{j} 1}\{\mathrm{~V}-\mathrm{man}[\mathrm{op}]\}$ & $/ \mathrm{t}^{\mathrm{j}} \mathrm{a} /$ & $\begin{array}{l}* \mathrm{~V} \text {-man[op] \& } \\
\quad * \mathrm{~V} \text {-pl[cor] }\end{array}$ & SHARE(V-pl[cor]) & $\operatorname{MAX}(\mathrm{V}-\operatorname{man}[\mathrm{op}])$ \\
\hline a. $\mathrm{t}^{\mathrm{j}^{1}}\{\mathrm{~V}-\mathrm{man}[\mathrm{op}]\}$ & $/ \mathrm{t}^{\mathrm{j}} \mathrm{a} /$ & & $* !$ & \\
\hline b. $\mathrm{t}^{\mathrm{j}}\left\{\mathrm{V}-\mathrm{pl}[\mathrm{cor}]_{1}\right\}$ & $/ \mathrm{t} \mathrm{j} /$ & & & $*$ \\
\hline $\begin{array}{ll}\text { c. } & \mathrm{t}^{\mathrm{j}^{1}}\left\{\mathrm{~V}-\mathrm{pl}[\mathrm{cor}]_{1},\right. \\
& \mathrm{V}-\mathrm{man}[\mathrm{op}]\}\end{array}$ & $/ \mathrm{t}^{\mathrm{j}} ? /$ & $* !$ & & \\
\hline
\end{tabular}

The reduction of the mid vowels after palatalized consonants proceeds in a similar way. In the case of /e/, V-manner[closed] has to be deleted just as in the case of /e/ following non-palatalized consonants, and it seems impossible to know whether spreading happens (and the relative ranking of SHARE(Vplace[coronal]) and $\operatorname{MAx}(\mathrm{V}$-place[coronal])), since the phonetic result is the same. This is shown in (39).

(39) Reduction of $/ \mathrm{t}_{\mathrm{e}} /$

\begin{tabular}{|c|c|c|c|c|}
\hline $\mathrm{t}^{\mathrm{j}^{1}}\left\{\mathrm{~V}-\mathrm{pl}[\mathrm{cor}]_{2}, \mathrm{~V}-\mathrm{man}[\mathrm{cl}]\right\}$ & $/ \mathrm{t}^{\mathrm{j}} \mathrm{e} /$ & $* \mathrm{~V}-\mathrm{man}[\mathrm{cl}]$ & SHARE(V-pl[cor $])$ & $\operatorname{MAX}(\mathrm{V}-\mathrm{pl}[\mathrm{cor}])$ \\
\hline a. $\begin{aligned} & \mathrm{t}^{\mathrm{j} 1}\left\{\mathrm{~V}-\mathrm{pl}[\mathrm{cor}]_{2},\right. \\
& \mathrm{V}-\mathrm{man}[\mathrm{cl}]\}\end{aligned}$ & $/ \mathrm{t}^{\mathrm{j}} \mathrm{e} /$ & $* !$ & $*$ & \\
\hline b. $\mathrm{t}^{\mathrm{j}^{1}}\left\{\mathrm{~V}-\mathrm{pl}[\mathrm{cor}]_{1}\right\}$ & $/ \mathrm{t}^{\mathrm{j}} \mathrm{i} /$ & & & $*$ \\
\hline c. $\mathrm{t}^{\mathrm{j}^{1}}\left\{\mathrm{~V}-\mathrm{pl}[\mathrm{cor}]_{2}\right\}$ & $/ \mathrm{t} \mathrm{i} /$ & & $*$ & \\
\hline $\begin{array}{c}\text { d. } \mathrm{t}^{\mathrm{j}^{1}}\left\{\mathrm{~V}-\mathrm{pl}[\mathrm{cor}]_{1},\right. \\
\mathrm{V}-\mathrm{man}[\mathrm{cl}]\}\end{array}$ & $/ \mathrm{t}^{\mathrm{j}} \mathrm{e} /$ & $* !$ & & \\
\hline
\end{tabular}

In the case of /o/, V-manner[closed] is deleted because of the markedness constraint driving vowel reduction in all other cases, while V-manner[open] is disallowed by the same mechanism as in (38). The tableau is shown in (40).

(40) Reduction of $/ \mathrm{t}_{\mathrm{O}} /$

\begin{tabular}{|c|c|c|c|c|c|}
\hline $\mathrm{t}^{\mathrm{j} 1}\{\mathrm{~V}-\mathrm{man}[\mathrm{cl}]\}$ & $/ \mathrm{t}^{\mathrm{j}} \mathrm{O} /$ & $\begin{array}{l}* \mathrm{~V}-\mathrm{pl}[\mathrm{cor}] \& \\
* \mathrm{~V}-\mathrm{man}[\mathrm{op}]\end{array}$ & $* \mathrm{~V}-\operatorname{man}[\mathrm{cl}]$ & $\begin{array}{c}\text { SHARE } \\
\text { (V-pl[cor]) }\end{array}$ & $\operatorname{MAX}(\mathrm{V}-\operatorname{man}[\mathrm{cl}])$ \\
\hline a. $\mathrm{t}^{\mathrm{j} 1}\{\mathrm{~V}-\mathrm{man}[\mathrm{cl}]\}$ & $/ \mathrm{t}^{\mathrm{j}} \mathrm{o} /$ & & $* !$ & * & \\
\hline b. $\mathrm{j}^{\mathrm{1} 1}\left\{\mathrm{~V}-\mathrm{p} 1[\mathrm{cor}]_{1}\right\}$ & $/ \mathrm{t}^{\mathrm{i}} \mathrm{i} /$ & & & & * \\
\hline $\begin{array}{ll}\text { c. } & \mathrm{t}^{\mathrm{j}}\left\{\mathrm{V}-\mathrm{pl}[\mathrm{cor}]_{1},\right. \\
& \mathrm{V}-\mathrm{man}[\mathrm{op}]\}\end{array}$ & $/ \mathrm{t}^{\mathrm{j}} ? /$ & $* !$ & & & * \\
\hline d. $\mathrm{t}^{\mathrm{j} 1}\{\mathrm{~V}-\operatorname{man}[\mathrm{op}]\}$ & $/ \mathrm{t}^{\mathrm{j}} \mathrm{a} /$ & & & $* !$ & * \\
\hline $\begin{aligned} \text { e. } & \mathrm{t}^{1}\left\{\mathrm{~V}-\mathrm{pl}[\mathrm{cor}]_{1},\right. \\
& \mathrm{V}-\mathrm{man}[\mathrm{cl}]\}\end{aligned}$ & $/ \mathrm{t}^{\mathrm{j}} \mathrm{e} /$ & & $* !$ & & \\
\hline
\end{tabular}


The complete ranking for Russian vowels is shown in Figure 5. It assumes that /i/ in unstressed syllables following palatalized consonants is due to spreading, i.e. that the winner in (39) is candidate (39b), but this is done for the sake of the argument, since there does not appear to be specific evidence either way.

In the next section I consider the facts of reduction following $/ \mathrm{ts} /, \mathrm{s} \mathrm{s} /$, and $/ \mathrm{z}^{\mathrm{w}} /$.

\subsection{Russian vowel reduction: The tricky case}

As discussed above, reduction following $\left[\mathrm{s}^{\mathrm{w}}\right],\left[\mathrm{z}^{\mathrm{w}}\right]$, and $[\mathrm{ts}]$ is often presented as an additional complication. Specifically, in older norms, these segments, which are historically palatalized (but synchronically non-palatalized), behave like palatalized consonants, in that they cause neutralization of all non-high vowels to /e/, rather than just neutralization of /o/ with /a/. In the modern norm, however, there seems to be a great deal of variation, at least across lexical items, as described in Section I.I.4 above.

First, I consider the case of [ts] mostly unproblematic in Modern Russian. Following this segment, /e/ neutralizes with /i/, as in (4I), but we have seen that this is in fact the normal pattern for both palatalized and nonpalatalized consonants.

(4I) (a) ['tsennoj] 'valuable'

(b) [tșịna] 'price'

With respect to the /o/-/a/ neutralization, it was remarked above that such words are extremely rare in Russian, and where evidence does appear, it seems that /ts/ behaves like an ordinary non-palatalized consonant (or at least one which does bear the V-place[coronal] feature).

As for $\left[\mathrm{s}^{\mathrm{w}}\right]$ and $\left[\mathrm{z}^{\mathrm{w}}\right]$, their behaviour is traditionally described as follows: in radical reduction, they behave like non-palatalized consonants, in that they are followed by [ə] where reduction happens (i.e. except where the vowel is $/ \mathrm{u} /$ ), and in moderate reduction they can behave like palatalized consonants in that they are followed by / $\mathrm{i} /$ corresponding to all underlying

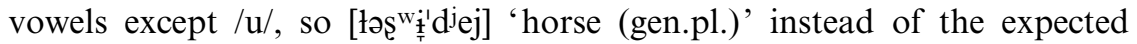
*[łəs $\left.{ }^{\mathrm{w}} \mathrm{e}^{\prime} \mathrm{d}^{\mathrm{j}} \mathrm{ej}\right]$, from underlying $/ \mathrm{los}^{\mathrm{w}} \mathrm{ad} \mathrm{j} /$.

The apparent paradox of the difference between radical and moderate reduction is easily solvable, since this difference is never phonologically relevant, as radical reduction is due merely to reduced duration. Since $\left[\mathrm{s}^{\mathrm{w}}\right]$ and $\left[\mathrm{z}^{\mathrm{w}}\right]$ are articulated with strong velarization and some labialization (Jones \& Ward 1969, Hamann 2004), it is not surprising that a short following vowel will be almost completely obscured by the formant transitions from the consonant. In particular, it is unrealistic to expect that an [i]-like segment can surface given the restrictions imposed by reduced duration, since the F2 transition of velarized/labialized consonants is much lower than the $2500 \mathrm{~Hz}$ 


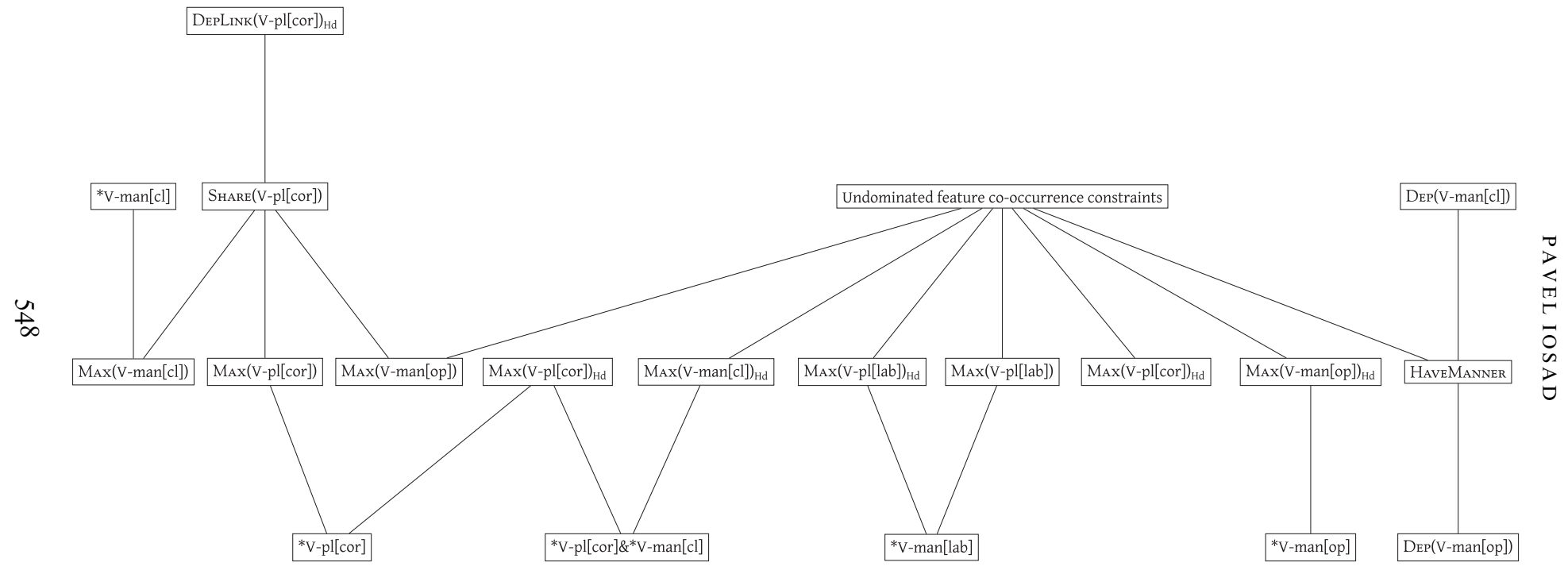

Figure 5

The complete ranking. 
required by [i]. In other words, it is not inconceivable that the vowel is actually /i/, but phonetic contingency makes it sound much more [ə]-like.

As for the neutralization pattern, the problem lies in the following: while the consonants are not palatalized on the surface, they behave as if they carried the same feature as palatalized ones (at least where they cause exceptional patterns of reduction). This apparent paradox is strengthened when we consider the consonant alternations of Russian. Specifically, both [ $\left.\mathrm{s}^{\mathrm{w}}\right]$ and $\left[\mathrm{z}^{\mathrm{w}}\right]$ in Russian are the outcomes of the processes of Velar Palatalization and Iotization, which are commonly assumed to be triggered by front vowels (Rubach 2000, Mołczanow 2007) and also output the palatalized [t $\mathfrak{f}^{\mathrm{j}}$. For this reason, Rubach $(2000,2007)$ and Mołczanow (2007) take the behaviour of these segments as evidence for multiple-level derivations in OT, postulating a 'backness switch' whereby these consonants are [-back] at intermediate levels in the derivation and become [+ back] on the way to the surface.

Within the tenets of the theory espoused in this paper, it behoves us to ask what evidence there is for the [+ back] specification in these consonants. For Rubach (2000) and Mołczanow (2007), the evidence is that they induce a phonological change from $/ \mathrm{i} /$ to $/ \mathbf{i} /$; however, here we assume that the difference between [i] and [i] is not phonological, and follows as part of the implementation of phonetically velarized consonants before /i/. In other words, if the phonetic implementation of a given segment - irrespective of its featural make-up - requires velarization, it will be followed, in transcription, by '[i]'. Consequently, the fact that a consonant is followed by '[i]' does not constitute evidence against a [-back] (or V-place[coronal]) specification.

In fact, if we assume that $/ \mathrm{s}^{\mathrm{w}} /$ and $/ \mathrm{z}^{\mathrm{w}} /$, along with $/ \mathrm{t}^{\mathrm{j}} /$, do bear the V-place[coronal] feature (see Iosad \& Morén-Duolljá 2012 for details), the exceptional pattern of vowel reduction follows automatically, in line with the analysis shown in the previous section. Thus, the 'backness switch' (i.e. the change of $/ \mathrm{i} /$ to ' [i] ') is a matter of phonetic implementation. Presumably the retroflexion/labialization of $\left[\mathrm{s}^{\mathrm{w}}\right]$ and $\left[\mathrm{z}^{\mathrm{w}}\right]$ is a kind of enhancement strategy, which improves perceptibility (Padgett \& Żygis 2007). It has, however, no bearing on the distinctive status of the phonological symbols involved, and thus need not be reflected in the phonological representation.

Within such a framework, the exceptional behaviour of $\left[\mathrm{s}^{\mathrm{w}}\right]$ and $\left[\mathrm{z}^{\mathrm{w}}\right]$ can be accounted for without recourse to multiple-level phonological derivations. In fact, this behaviour follows directly from the feed-forward modular architecture of grammar.

However, some issues arise with those cases where $\left[\mathrm{s}^{\mathrm{w}}\right]$ and $\left[\mathrm{z}^{\mathrm{w}}\right]$ behave as if they were non-palatalized consonants. This case obviously involves variation, and variation can be dealt with in any number of ways in current phonological theory. I propose that cases where $\left[\mathrm{s}^{\mathrm{w}}\right]$ and $\left[\mathrm{z}^{\mathrm{w}}\right]$ behave like non-palatalized consonants represent a new variety of Modern Russian. Here, I consider two possibilities. 
One option is that unlike other cases of vowel reduction, vowel reduction following $\left[\mathrm{s}^{\mathrm{w}}\right]$ and $\left[\mathrm{z}^{\mathrm{w}}\right]$ no longer represents a phonological process, but rather selection of different allomorphs (a similar route is taken by Crosswhite 2000). How this selection is undertaken is not crucial here (but see Wolf 2008 for discussion of some possibilities). This allows us to uphold the generalization regarding the behaviour of V-place[coronal] segments in the language otherwise.

Another option is assuming that for some speakers the phonological representations have actually changed, so that $/ \mathrm{S}^{\mathrm{w}} /$ and $/ \mathrm{z}^{\mathrm{w}} /$ no longer have a V-place[coronal] feature. Thus, the 'new' cases where /o/-/a/ remain distinct from $/ \mathrm{e} / / \mathrm{i} / \mathrm{n}$ now represent regular behaviour, while the older patterns are now exceptional. This option has the advantage of having a simpler phonetic implementation component; however, this means that the generalizations with respect to the behaviour of $\left[\mathrm{s}^{\mathrm{w}}\right]$ and $\left[\mathrm{z}^{\mathrm{w}}\right]$ in palatalization-related processes are more difficult (if at all possible) to express. I would like to propose, however, that it is not infeasible that those systems where $\left[\mathrm{s}^{\mathrm{w}}\right]$ and $\left[\mathrm{z}^{\mathrm{w}}\right]$ behave like non-palatalized segments are a natural result of the life-cycle of palatalization-related rules. Specifically, both Velar Palatalization and Iotization are 'old' rules with a relatively small degree of regularity. In terms of Lexical Phonology, they are often assigned to deeper levels, such as the stem level (Plapp 1999, Blumenfeld 2003), and Rubach (2000) explicitly proposes viewing Iotization as a morphological rather than phonological phenomenon. It would thus not be surprising if for some speakers these rules have by now ceased to be a part of the phonological computation, and have been relegated into (or have ascended to) the morphology (for a concise statement of a framework which explicitly deals with these life-cycles, see Bermúdez-Otero 2007).

If this is correct, and Velar Palatalization and Iotization are no longer part of the phonological system of Russian, there is no robust evidence for $/ \mathrm{s}^{\mathrm{w}} /$ and $/ \mathrm{z}_{\mathrm{c}} \mathrm{w} /$ bearing the feature $\mathrm{V}$-place[coronal], and then the 'new' vowel reduction behaviour is expected. The strong prediction made here is that precisely those speakers who have abandoned the phonological palatalizationrelated rules will tend to generalize the new reduction pattern. This prediction is at least potentially testable, but clearly needs further work. ${ }^{24}$

To summarize, in this section I have proposed a new account of the Russian vowel inventory and vowel reduction processes. I have shown that a minimalist feature theory, together with a non-trivial phonetic implementation component, can allow us to resolve a number of issues identified in Section I.

[24] There is a well-documented tendency for Russian verbs to abandon morphological classes which require Velar Palatalization and Iotization in the stems (Nesset 2008), which suggests at least that these rules are visible to the morphology in some ways. Harasowska (1999) is an interesting study of the status of some similar alternations in the related language Rusyn. 
First, the theory proposed here enables us to state the reduction patterns in a very simple and straightforward way. Second, the interpretation of the phenomena of Russian reduction proposed in Section I.2 has also allowed us to dispense with rather complicated mechanisms which would otherwise be needed to derive the difference between moderate and radical reduction, and eliminate the problem of the non-contrastive segments. Third, a non-trivial phonetics-phonology interface offers a solution to the problem of backness mismatches, which has previously been argued to represent a difficulty for monostratal OT.

In the next section, I consider some other accounts of vowel reduction in Russian which can be found in the literature.

\section{OThER APPROACHES TO VOWEL REDUCtion}

Vowel reduction in Standard Russian has been the subject of numerous studies in recent years. In this section I consider one alternative account of vowel reduction following palatalized consonants, which is more in keeping with several recent approaches. Then I concentrate on some specific details of accounts proposed by Crosswhite (2000), Padgett (2004), and Hermans (2008), and also show the importance of Russian data for the universalspecification theory of de Lacy (2006).

\section{I Sequential markedness}

In Section 2.4 I presented an account of reduction following palatalized consonants which uses a constraint actively promoting the spreading of a $\mathrm{V}$-place[coronal] feature. Most previous accounts of vowel reduction use a different approach, which I briefly consider in this section.

Instead of being actively promoted, spreading can be viewed as a last resort strategy to repair an illicit representation with an empty root node. From the analytical viewpoint, the advantage of this strategy is that no additional rankings must be adduced to exclude unattested spreading. However, it needs an additional constraint to motivate the exclusion of /a/ following palatalized consonants.

The simplest way to do this is to set up a constraint that penalizes the sequence of a palatalized consonant and the low vowel /a/. Much of the existing literature does just that: Crosswhite (2000) proposes a constraint $\mathrm{C}$ [ + front $]$ ('in unstressed syllables, palatalized consonants are followed by [+front] vowels'), and Padgett (2004) uses $\mathrm{Cj}_{\text {[+hi] }}$ ('after a palatalized consonant, a short vowel is [+hi]'). In effect, this is a type of sequential markedness constraint.

It is possible to 'translate' this account into the representational theory espoused here. The relevant constraint would ban the sequence of a consonant bearing the V-place[coronal] feature and any segment with a 
non-empty V-manner node. However, this raises a number of issues, of which the most significant is the descriptive nature of the constraint. All three formulations proposed in this and the preceding paragraphs, when taken at face value, merely restate the facts. The constraint plays a role in producing the patterns, but does not contribute much to explaining their reason.

The account of reduction following palatalized consonants as a spreading phenomenon, presented in Section 2.4 above, on the other hand, makes the connection between the reason behind the process and the pattern itself very explicit: /i/ is the outcome of reduction following palatalized consonant precisely because [i] and the consonants have the same feature.

The sequential markedness constraint can be said to be explanatory by virtue of its grounding in the phonetic or perceptual system (this is the line explicitly taken by Padgett 2003, 2004). However, the present paper is set within the context of a theory which seeks a separation between phonetic and phonological concerns rather than their integration (see Anderson I98I).

Sequential markedness is certainly a possible solution in terms of empirical adequacy. My conclusion, however, is that the account presented in Section 2.4 is preferable within the context of PSM, for two reasons. First, it makes very explicit the connection between the reason for the deviant behaviour of palatalized consonants as triggers of vowel reduction and the sound pattern itself. Second, the explanation it provides is purely phonological, and does not need recourse to factors outside of the phonological computation to achieve explanatory adequacy.

\subsection{Phonetically based phonology}

Crosswhite (2000, 200I) presents the reduction pattern of Modern Standard Russian within the context of reduction patterns in other Eastern Slavic dialects. She distinguishes 'radical' and 'moderate' reduction as being characteristic of non-moraic and moraic positions respectively. As we have seen in Section I.2, this move does not appear to be warranted by the data, making some of the theoretical machinery she employs to derive this distinction redundant (at least for Russian).

However, there are other empirical and conceptual concerns with her proposal. Both of these are related to the key constraint driving the reduction of mid vowels, which she calls LicENSENonPERIPHERAL/STRESS, i.e. 'only peripheral vowels are allowed in unstressed syllables'. First, as pointed out by de Lacy (2006), the inclusion of such a constraint into the universal constraint set predicts the existence of sonority-based stress systems where stress is attracted to non-peripheral vowels at the expense of peripheral ones. Specifically, if both the licensing constraint and faithfulness dominate other constraints on stress placement, it is better to avoid violating the licensing 
constraint by placing stress on the non-peripheral vowel than by vowel reduction. Such a system does not seem to be attested. (However, see Section 3.6 below for more discussion of this matter.)

On the conceptual side, this constraint, just like the sequential markedness constraint discussed in Section 3.I, is not explanatory in itself, and must make reference to external grounding (which is, of course, the essence of the research program that Crosswhite 200I works within). In that sense, the proposal contained in this paper can be said to be more parsimonious, since it allows deriving the vowel reduction patterns using only mechanisms that are independently founded in the phonological computation.

\subsection{Dispersion-based approaches}

A dispersion-based approach to vowel reduction in Standard Russian is offered by Padgett (2004) and Padgett \& Tabain (2005). Padgett \& Tabain (2005) present three important findings, based on a phonetic study. First, they claim that the neutralization of /i/ and /e/ is incomplete, contrary to the impressionistic descriptions. Second, they report significant raising of the vowel space floor in unstressed positions, and some lowering of the vowel space ceiling in unstressed positions following non-palatalized consonants, which is consistent with a theory viewing vowel reduction as the direct result of undershoot. Third, they show that dispersion-theoretic claims with respect to equal spacing of vowels in all positions do not hold up for Russian in the simplistic form where spacing is measured in terms of simple formant values.

The first fact is not surprising at all, given Padgett \& Tabain's (2005) set of informants, which included speakers from outside Moscow, and notably from regions such as St Petersburg and Ukraine. As pointed out above in Section I.I.I, the local dialects in some of these regions may differ from Central Russian in the phonetic patterns of vowel reduction. Moreover, a significant part of their sample are Russian émigrés in Australia, who left the country after 19I7: Padgett \& Tabain (2005) do argue that Russian is wellpreserved among this group, but given that the norm where /e/ and /i/ are neutralized is relatively new, we might well be dealing with preservation of the older norm. The plots in Padgett \& Tabain (2005) show that their informant MK, who is perhaps likeliest to speak a newer Moscow norm, is strongly neutralizing. ${ }^{25}$

The claims with respect to the role of phonetic factors do not bear much on the phonological interpretation-possibly except where they seem to demonstrate that phonetic factors are not the only ones relevant in reduction. Thus, Padgett \& Tabain (2005) note that in the first pretonic syllable, the distance between the allophone of /a/ (the traditional [ $\mathrm{k}]$ ) and of the

[25] This speaker was born in Moscow, was 45 years old at the time of the experiment, and came to Australia quite late in her life, so strong interference from English is unlikely. 
other vowels is greater than might be expected if reduction was due to mechanical undershoot. This can be consistent with the suggestion that the phonetic target in this position is in fact the low vowel /a/, as suggested by Barnes (2006, 2007).

Thus, while the study of Russian vowel reduction by Padgett \& Tabain (2005) is extremely valuable, in that it goes a long way towards demonstrating the phonetic factors involved in the realization of vowels in unstressed positions, it seems that dispersion theory cannot fully account for the observed facts. In particular, dispersion theory can explain why the vowel space is cramped, but not why this cramping leads to the mid vowels neutralizing in 'different directions': lowering for the back vowel and raising for the front one. These questions are discussed by Padgett (2004).

Padgett (2004) attempts to express dispersion-theoretic insights in terms of OT. Apart from rather orthodox faithfulness and markedness constraints, he introduces a number of functionally grounded constraints, such as * $\breve{V}[+$ low jaw], which serves to reproduce the floor raising effects, and ${ }^{*}\left[\mathrm{Cj}^{2}\right]$. These constraints are all subject to the criticisms provided above in Section 3.I.

More importantly, Padgett's (2004) analysis runs into empirical problems. First, his constraint * $\breve{V}[+$ low jaw] excludes all non-high vowels except [ə] from unstressed position; as a consequence, he has to assume that phonetic [ $\mathrm{r}]$ in the first pretonic syllable is phonologically /o/: a suggestion that appears inconsistent with the data adduced above, in Section I.2. Second, Padgett (2004) cannot provide an account of the input-output mappings, since no ranking of the IDENT constraints (for the orthodox features [back], [high] and [round]) can produce the necessary patterns. He suggests that either neutralization to [i] following palatalized consonants is a phonetic effect, and that phonologically the result is [ə], or that Russian vowel reduction is an instance of opacity, which must be handled by a multi-level OT computation.

The first option is difficult to reconcile with the approach espoused in this paper because I assume that / $/$ / is not part of the Russian vowel inventory, for reasons discussed at length above. Unfortunately experimental data that could settle this issue (for instance, an experiment along the lines of that by Barnes 2007 but involving /e/ and /i/) do not seem to be available. ${ }^{26}$

As for the second option, I submit that the problem is largely due to the inadequacy of the featural specifications used by Padgett (2004), which do not take into account the segments' phonological activity. However, once the representations are amended, as proposed in the present paper, dispersiontheoretic mechanisms are unnecessary, since featural markedness alone can provide an explanation of the pattern.

[26] One suggestive piece of evidence is provided by the behaviour of word-initial unstressed /e/, as in example (6) above: despite the prolonged duration in word-initial position, the sound is definitely [I]- like rather than [ə]-like. However, given the lack of segmental alternations, this evidence is not conclusive. 
It must be emphasized that the criticism of the dispersion-based phonological account of Russian vowel reduction offered in this section does not constitute a rejection of a possible role for dispersion factors in the sound pattern. The phonological representations used in the present account are heavily underspecified, in that they clearly do not contain enough information for the phonetic implementation module to accurately place the vowels within the vowel space. It remains entirely possible, and in fact extremely likely in view of the findings of Padgett \& Tabain (2005), that factors such as dispersion are to a significant degree responsible for "filling in the blanks' in the representations, i.e. in providing those phonetic properties which cannot be said to follow from the output of the phonological module (see also Keating 1988). ${ }^{27}$

\subsection{Element Theory}

Hermans (2008) provides an account of Russian vowel reduction in terms of Element Theory and constraints on sonority for (non-)designated terminal elements as proposed by de Lacy (2006). The representations he uses bear an obvious affinity to the ones proposed in the present paper, in that mid vowels are assumed to be complex segments composed of several primes (elements), while peripheral vowels are simpler, consisting of just one element (see also Harris 2005). However, Hermans (2008) seems to assume that vowel features are assigned in a universal manner, possibly based on the segments' phonetic properties, rather than on the basis of their phonological behaviour in a given language. Thus, for example he assumes that [e] is cross-linguistically specified as $\{I, A ; I\}$ : that is, the head position is occupied by the elements $\{I\}$ and $\{\mathrm{A}\}$, and the dependent position is occupied by $\{\mathrm{I}\}$.

Further, Hermans (2008) assumes a set of Presence and AbSENCE constraints which correspond to de Lacy's (2006) constraints on the sonority of (non-)designated terminal elements. This is possible because, as is commonly assumed in Element Theory and related approaches, sonority is represented structurally, as the position of the $\{\mathrm{A}\}$ element. A crucial difference is that de Lacy (2006) essentially defines sonority in terms of height (barring the schwa and high central vowels), and thus for him the mid lax vowels [ $\varepsilon$ o $]$ are less sonorous than [a], while for Hermans (2008) these are the most sonorous vowels, since they contain the element $\{\mathrm{A}\}$ in both head and dependent positions.

In terms of triggering, Hermans (2008) essentially follows Crosswhite (200I) in distinguishing between moderate and radical reduction, thus inheriting many of her problematic assumptions, in particular the presence of a

[27] I remain agnostic as to whether dispersion is an independent principle of the grammar (Flemming 2002; Padgett 2003, 2004) or emergent (de Boer 200I, Boersma \& Hamann 2008, Hall 20II). 
phonological segment /a/. Most importantly, his account predicts that /a/ should be impossible in unstressed syllables outside the first pretonic position, since the appearance of the $\{\mathrm{A}\}$ element is promoted by constraints applying to what he calls the head foot in the word. This is inconsistent with the results reported in Section I.2 above.

The account by Hermans (2008) does have an advantage over that by Crosswhite (200I) in that the externally grounded licensing constraint is replaced, as in the present paper, by a constraint which makes much more direct reference to feature structure. Hermans (2008) proposes that Russian mid vowels are lax and thus maximally sonorous, which renders them amenable to reduction: since highly sonorous segments are dispreferred in non-head positions, they will either attract stress (which, Hermans proposes, is the case in Dutch, thus implicitly rebutting de Lacy's criticism regarding factorial typology) or reduce easily. However, the assumption of laxness as a phonologically active feature in Russian is problematic. First, there is no contrast between tense and lax mid vowels, so if specifications are assigned economically, the assumption of redundant structure is unwarranted. Second, the phonetic implications are difficult to disentangle. Given that there is significant coarticulatory influence on Russian vowels from preceding consonants, and especially in the case of the front vowels (EvansRomaine 1998, Padgett 200I, Kochetov 2002), formant data are to be interpreted with great care (see also Section 3.5 on this point). It seems that there is little positive evidence for the contrastive laxness of Standard Russian vowels. Examination of the formant plots and figures in several sources (Timberlake 2004, Kniazev \& Požarickaya 2005, Padgett \& Tabain 2005) seems to show that while /e/ is indeed a rather low vowel $[\varepsilon], / o /$ tends to be quite high, thus possibly [o]. ${ }^{28}$

Moreover, the assumption that mid lax vowels are maximally sonorous might be problematic in view of the data from languages such as Gujarati, where it is the low vowel does seem that is more sonorous in the relevant sense, i.e. acts as a better stress attractor, as in [pəhe'lã] 'in the past' (de Lacy 2006: Section 5.3.2.I).

To summarize, the account by Hermans (2008) incorporates a number of problematic assumptions, both in his analysis of the distribution of various reduction types (some of which he inherits from Crosswhite 2000) and in his representational proposals.

\subsection{Universal specification and input-output mapping}

Many of the proposals described in the previous subsections follow an essentially similar schema: first some mechanism is proposed to reduce the

[28] For extended discussion of the uncritical use of features such as [tense], [lax] and [ATR], see Lodge (2009). 


\begin{tabular}{lccccc}
\hline Vowel & {$[$ high $]$} & {$[$ low $]$} & {$[$ back] } & [round] & [ATR] \\
\hline$/ \mathrm{i} /$ & + & - & - & - & + \\
$/ \mathrm{u} /$ & + & - & + & + & + \\
$/ \mathrm{e} /$ & - & - & - & - & + \\
$/ \mathrm{o} /$ & - & - & + & + & + \\
$/ \mathrm{\varepsilon} /$ & - & - & - & - & - \\
$/ \mathrm{J} /$ & - & - & + & + & - \\
$/ \mathrm{a} /$ & - & + & - & - & - \\
\hline
\end{tabular}

Table 3

Universal featural specifications for vowels (de Lacy 2006).

vowel inventory from five vowels to three or two, and then more orthodox faithfulness constraints are deployed to get the correct input-output mappings. The latter part often proves problematic, as acknowledged especially by Padgett (2004). In this section I demonstrate that this problem is largely due to the assumption of universal feature specification and the uncritical use of features based on phonetic substance. Specifically, I take issue with the (often unspoken) assumption that segments which are phonetically similar in different languages have essentially the same, possibly fully specified, representation in terms of phonological features. I show that this creates two significant problems when faced with the input-output mappings involved in Russian vowel reduction.

A recent proposal arguing at length for universal feature specifications is that by de Lacy (2006). To account for vowel reduction, he proposes a set of universally valid specifications (shown in Table 3) and a set of markedness constraints demanding highly sonorous vowels in designated terminal elements ('heads') and low-sonority vowels in nondesignated ones. These markedness constraints can derive a triangular inventory /i u a/ easily by ranking ${ }^{*} \Delta_{\sigma} \leqslant\{$ e,o $\}$ (i.e. the constraint penalizing nuclei with vowels less sonorous than /a/) above faithfulness, but below IDENT[ \pm high]. This is demonstrated in (43), which shows how vowel reduction is analysed in (Standard) Belarusian, a language closely related to Russian. In Belarusian, all non-high vowels are realized as [a] in unstressed syllables.

(42) (a) ['retfka] 'river (diminutive)'

(b) $[\mathrm{ra}$ 'ka] 'river'

(c) ['m $\left.\mathrm{m}^{\mathrm{j} o t}\right]$ 'honey'

(d) [mja'dovi] 'honey (adj.)' 
(43) Vowel reduction in Belarusian (de Lacy 2006: 32I)

\begin{tabular}{|c|c|c|c|c|}
\hline /mºdovi/ & $\sigma^{\prime}$-IDENT $[ \pm$ low $]$ & IDENT $[ \pm$ high $]$ & $* \Delta_{\sigma} \leqslant\{\mathrm{e}, \mathrm{o}\}$ & $\operatorname{IDENT}[ \pm$ low $]$ \\
\hline a. $m^{j} a^{\prime} d a v \dot{i}$ & $* !$ & & * & \\
\hline b. $\mathrm{m}^{\mathrm{j}} \mathrm{a}^{\prime}$ dova & & $* !$ & * & * \\
\hline c. $\mathrm{m}^{\mathrm{j}} \mathrm{o}^{\prime}$ dovi & & & $* * * !$ & \\
\hline d. $\mathrm{m}^{\mathrm{j}} \mathrm{a}^{\prime} \mathrm{dov} \dot{\mathrm{f}}$ & & & $* *$ & \\
\hline
\end{tabular}

In (43), the stressed syllable is protected by positional faithfulness (as in the present account), high vowels are protected by high-ranking faithfulness to height features, while mid vowels are free to lower in order to satisfy the high-sonority requirement.

The crucial difference between languages such as Belarusian on the one hand and Russian on the other hand is that in the former, mid vowels behave identically with respect to height: in Belarusian, they uniformly lower. This effect is achieved by the high ranking of a faithfulness constraint to some feature which is then preserved in the input-output mapping: in the case of Belarusian, the feature is [high].

In Modern Standard Russian, of course, mid vowels behave differently:/e/ raises while /o/ lowers. This presents a very significant problem for the theory advanced by de Lacy (2006), which assumes that vowels have consistent featural representations cross-linguistically.

Let us assume that the Russian vowels are phonologically /e/ and /o/: above I have noted that it is very difficult to determine phonetically whether Russian mid vowels are /e o/ or / $\varepsilon \mathrm{o} /$, but this assumption will serve for the sake of the present argument. Let us also assume that the Russian /a/ is indeed $/ \mathrm{a} /$ and not $/ \mathrm{a} /$ (its [ + back] correspondent). If we ignore the [ATR] feature, above argued to be redundant, there is no ranking which can account for the input-output mapping needed for Russian. This is demonstrated by the comparative tableau in Table 4 ; the result does not change if the mid vowels are $/ \varepsilon$ o/ or the low vowel is /a/.

The tableau in Table 4 is INCONSISTENT, in that the operation of fusion on all its rows yields a row consisting only of L symbols (for details of the procedure, see Prince 2002 and references therein). In other words, no ranking of the constraints enumerated in Table 4 can produce the desired outcome.

It is possible to provide an account of Russian reduction if /e/ and /o/ do not have symmetrical feature structures. Specifically, if it is assumed that Russian /e/ is [+ATR] and Russian /o/ is [-ATR] (i.e./o/), then the relevant neutralization patterns can be derived. The analysis is then essentially identical to the analysis of Bergüner Romansh proposed by de Lacy (2006), but with inventory gaps. In Bergüner Romansh, unstressed /e/ and /o/ raise 
VOWEL REDUCTION IN RUSSIAN

\begin{tabular}{|l|c|c|c|c|c|c|c|}
\hline Input & $\mathrm{W} \sim \mathrm{L}$ & IDENT[rd] & IDENT[hi] & IDENT[lo] & IDENT[bk] & $*-\Delta_{\sigma} \geqslant\{\mathrm{e}, \mathrm{o}$ & $\Delta_{\omega} \geqslant\{\mathrm{e}, \mathrm{o}$ \\
\hline \multirow{3}{*}{$/ \mathrm{to} /$} & {$[\mathrm{ta}] \sim[\mathrm{to}]$} & $\mathrm{L}$ & & $\mathrm{L}$ & $\mathrm{L}$ & & $\mathrm{W}$ \\
\cline { 2 - 9 } & {$[\mathrm{ta}] \sim[\mathrm{ti}]$} & & $\mathrm{W}$ & $\mathrm{L}$ & & $\mathrm{L}$ & $\mathrm{W}$ \\
\cline { 2 - 9 } & {$[\mathrm{ta}] \sim[\mathrm{te}]$} & & & $\mathrm{L}$ & & & $\mathrm{W}$ \\
\cline { 2 - 9 } & {$[\mathrm{ta}] \sim[\mathrm{tu}]$} & $\mathrm{L}$ & $\mathrm{W}$ & $\mathrm{L}$ & $\mathrm{L}$ & $\mathrm{L}$ & $\mathrm{W}$ \\
\hline$/ \mathrm{te} /$ & {$[\mathrm{ti}] \sim[\mathrm{ta}]$} & & $\mathrm{L}$ & $\mathrm{W}$ & $\mathrm{L}$ & $\mathrm{W}$ & \\
\cline { 2 - 9 } & {$[\mathrm{ti}] \sim[\mathrm{to}]$} & $\mathrm{W}$ & $\mathrm{L}$ & & $\mathrm{L}$ & $\mathrm{W}$ & \\
\cline { 2 - 9 } & {$[\mathrm{ti}] \sim[\mathrm{te}]$} & & $\mathrm{L}$ & & & $\mathrm{W}$ & \\
\cline { 2 - 9 } & {$[\mathrm{ti}] \sim[\mathrm{tu}]$} & $\mathrm{W}$ & & & $\mathrm{L}$ & & \\
\hline \multirow{3}{*}{$/ \mathrm{ta} /$} & {$[\mathrm{ta}] \sim[\mathrm{ti}]$} & & $\mathrm{W}$ & $\mathrm{W}$ & & $\mathrm{L}$ & $\mathrm{W}$ \\
\cline { 2 - 9 } & {$[\mathrm{ta}] \sim[\mathrm{tu}]$} & $\mathrm{W}$ & $\mathrm{W}$ & $\mathrm{W}$ & $\mathrm{W}$ & $\mathrm{L}$ & $\mathrm{W}$ \\
\hline$/ \mathrm{ti} /$ & {$[\mathrm{ti}] \sim[\mathrm{ta}]$} & & $\mathrm{W}$ & $\mathrm{W}$ & & $\mathrm{W}$ & $\mathrm{L}$ \\
\hline$/ \mathrm{tu} /$ & {$[\mathrm{tu}] \sim[\mathrm{ta}]$} & $\mathrm{W}$ & $\mathrm{W}$ & $\mathrm{W}$ & $\mathrm{W}$ & $\mathrm{W}$ & $\mathrm{L}$ \\
\hline
\end{tabular}

Table 4

Comparative tableau for Russian vowel reduction ([ATR] excluded).

while $/ \varepsilon /$ and $/ \mathrm{s} /$ lower. For this system to work, the constraint IDENT[ \pm ATR] must be ranked above all constraint driving the reduction of mid vowels. This is demonstrated in (44) and (45), which are reproduced from de Lacy (2006: 323$)^{29}$

\section{(44) Reduction of /e/ in Bergüner Romansh}

\begin{tabular}{|c|c|c|}
\hline$/$ ze-uks/ & $*-\Delta_{\omega} \geqslant\{$ e, $\mathrm{o}\}$ & IDENT[ \pm high $]$ \\
\hline a. 3 e.'uks & $* !$ & \\
\hline b. 3i.'uks & & $* !$ \\
\hline
\end{tabular}

[29] The claim that [0] neutralizes with /a/ is taken from Kamprath (1987), but she does not show relevant alternations. This claim is in fact surprising considering the demonstration by Lutta (I923: Section II5) that historical *o in unstressed syllables yields / $\mathrm{u} /$ in Bergüner Romansh, e.g. Vulgar Latin Comune, Bergüner Romansh kumén 'village gathering', and see pairs such as pólof 'finger' (Lutta 1923: Section 78), putdjérr 'finger-sized object (German Fingerling)' (Lutta I923: Section II5). A potential source of ['o] [a] alternations is the shift of stressed *a to 0 before nasals, as in Vulgar Latin GRANDE, Bergüner Romansh gront 'big': since unstressed *a remained unchanged, one might imagine such alternations to appear, even though it remains unclear to what extent they can synchronically be analysed as an $/ \mathrm{o} / \rightarrow[\mathrm{a}]$ mapping rather than $/ \mathrm{a} / \rightarrow[0]$. In any case, it appears that even if the $/ \mathrm{J} /$ $\rightarrow$ [a] mapping is possible in Bergüner Romansh, it is at the very least not as regular as it would appear from de Lacy (2006). However, this is not a crucial point, inasmuch as an $/ \mathrm{o} /$ $\rightarrow[\mathrm{u}]$ mapping can be accounted for in de Lacy's (2006) system by assuming highly ranked IDENT $[ \pm$ round $]$. 
(45) Reduction of / $/ \varepsilon /$ in Bergüner Romansh

\begin{tabular}{|l|l|l|c|c|c|}
\hline \multicolumn{2}{|l|}{$/$ vend-eks/ } & IDENT $[ \pm$ ATR $]$ & $*-\Delta_{\omega} \geqslant\{\mathrm{e}, \mathrm{o}\}$ & $* \Delta_{\sigma} \leqslant\{\varepsilon, \mathrm{o}\}$ \\
\hline & a. & vin'd-eks & $* !$ & & $*$ \\
\hline & b. & ven'd-eks & & $*$ & $* * !$ \\
\hline & c. & van'd-eks & & $*$ & $*$ \\
\hline
\end{tabular}

There are three objections to such an analysis of Modern Standard Russian. First, as argued above, from a phonetic perspective the assumption that the Russian inventory is /i e a $\mathrm{o}$ / is not extremely well-founded: even if an asymmetry between the mid vowels exists, it goes in precisely the opposite direction.

Two other objections are more theory-oriented. First, the [ATR] feature is entirely redundant for the purposes of contrast: [ - high - low] vowels are distinguished by [back] (and [round]) ${ }^{30}$ Whether redundant features are phonologically active is a difficult question to answer, but see Dresher (2009) for arguments that they are not. Third, the analysis in terms of [ATR] specifications goes against the grain of de Lacy's (2006) proposals, in that it essentially subverts Richness of the Base: if Russian is like Bergüner Romansh with a smaller inventory, we expect input /o/ to map to /u/ and input $/ \varepsilon /$ to map to $/ a /$. This statement is very difficult to falsify or verify (as with many Richness of the Base statements), but in any case the analysis of Russian using universal feature specifications crucially relies on the properties of the input representations, which is something that the whole research programme represented by de Lacy (2006) aims to avoid.

An anonymous $J L$ referee points out that the problem shown in Table 4 is in large measure due to the nature of the constraints employed by de Lacy (2006). A relatively orthodox constraint or set of constraints militating against mid vowels, however represented, in weak position is satisfied whenever a non-mid vowel appears on the surface, and does not make reference to the relative sonority of the possible repairs. The constraints on sonority used by de Lacy (2006) prefer a certain kind of repair (uniform reduction or increase in sonority as appropriate), and this uniformity can only be defeated by featural identity constraints, as in the case of Bergüner Romansh, where [0] appears to resist the sonority increase in order to ensure faithfulness to the value of [round].

[30] In the spirit of Dresher (2009), an inventory /i u e 0 a/ could use [ATR] high on the contrastive hierarchy, thus using it as a distinctive feature: e.g. the hierarchy [ATR] $>$ [round] $>$ [high] can classify this inventory. However, it is not obvious what the motivation for reduction would be in this account (other than stipulations such as sonority or prohibitions against non-peripheral vowels), since mid vowels do not pattern together. 


\begin{tabular}{|l|c|c|c|c|c|c|}
\hline Input & $\mathrm{W} \sim \mathrm{L}$ & $\mathrm{ID}[\mathrm{hi}]$ & $\mathrm{ID}[\mathrm{lo}]$ & $\mathrm{ID}[\mathrm{bk}]$ & $\mathrm{ID}[\mathrm{rd}]$ & $*$ MID \\
\hline \multirow{4}{*}{$/ \mathrm{to} /$} & {$[\mathrm{ta}] \sim[\mathrm{to}]$} & & $\mathrm{L}$ & $\mathrm{L}$ & $\mathrm{L}$ & $\mathrm{W}$ \\
\hline & {$[\mathrm{ta}] \sim[\mathrm{te}]$} & & $\mathrm{L}$ & & & $\mathrm{W}$ \\
\hline & {$[\mathrm{ta}] \sim[\mathrm{ti}]$} & $\mathrm{W}$ & $\mathrm{L}$ & & & \\
\cline { 2 - 7 } & {$[\mathrm{ta}] \sim[\mathrm{tu}]$} & $\mathrm{W}$ & $\mathrm{L}$ & $\mathrm{L}$ & $\mathrm{L}$ & \\
\hline \multirow{4}{*}{$/ \mathrm{te} /$} & {$[\mathrm{ti}] \sim[\mathrm{to}]$} & $\mathrm{L}$ & & $\mathrm{W}$ & $\mathrm{W}$ & $\mathrm{W}$ \\
\cline { 2 - 8 } & {$[\mathrm{ti}] \sim[\mathrm{ta}]$} & $\mathrm{L}$ & $\mathrm{W}$ & & & \\
\cline { 2 - 7 } & {$[\mathrm{ti}] \sim[\mathrm{te}]$} & $\mathrm{L}$ & & & & $\mathrm{W}$ \\
\hline
\end{tabular}

Table 5

No solution if $/ \mathrm{a} /$ is $[-\mathrm{bk}]$.

The referee notes that if Russian /a/ is assumed to be [+ back], then the ranking in (46) can account for the pattern of vowel reduction.

$$
\text { (46) Positional faithfulness >> ID[bk], *MID >> ID[hi] >> ID[rd], ID[bk] }
$$

Under this ranking, the back mid vowel [o] cannot raise because of highranking faithfulness to [hi], so it lowers instead. The mid front vowel [e] cannot resist raising, because lowering would involve a violation of highly ranked ID[bk]. This is an attractive solution from the perspective of the OT grammar, but I suggest that it faces exactly the same problem in terms of universal feature specification as the account within de Lacy's (2006) system sketched above.

This is because just as the Bergüner-Romansh-style account of Russian has to rely on /e/ being [+ATR] and /o/ being [-ATR], so the solution shown in (46) can only work if /a/ is assumed to be $[+$ back]: in fact, no ranking can derive the pattern if [a] is assumed to be [-back], as shown in Table 5. Both of these accounts crucially rely on some input specification.

This is problematic both empirically and conceptually. From an empirical perspective, Russian [a] is clearly different from the low back unrounded vowel [a]: sources consistently describe it as a central vowel or even a relatively front vowel, with $\mathrm{F}_{2}$ values of around $500 \mathrm{~Hz}$ compared to about $200 \mathrm{~Hz}$ for back vowels such as [o] and [u]. What this means from a conceptual perspective is that for any of the solutions discussed in this section to work, one must necessarily assume that the learner has to abstract from some aspects of the relevant segments' phonetic realization and attend to the phonological pattern to identify the correct feature specification. In other 
words, the mapping between phonetic signal and phonological representations must be learned, and does not come 'for free' as part of Universal Grammar (de Boer 200I, Boersma \& Hamann 2008, Boersma 2009). Moreover, the learning must crucially make reference to the phonological patterning of the segments (Mielke 2007, Morén 2007, Blaho 2008, Dresher 2009).

To summarize, in this section I have shown that accounts of vowel reduction in Russian which solely rely on the phonological computation to derive the observed sound pattern, without regard to the set-up of phonological representations, face significant empirical and conceptual problems. I suggest that representational variation across languages is not only real, but far from trivial, and cannot be entirely derived from the computation, at least as this latter is understood in commonly accepted approaches. ${ }^{31}$

In the next section I reconsider the specific importance of the Parallel Structures Model for the present paper.

\subsection{The relevance of PSM and substance-free phonology}

So far, the intent of this paper has been threefold. I have started with defending a specific approach to the relationship between phonetics and phonology and exploring its implications for the analysis of vowel reduction in Modern Standard Russian, following work by Barnes (2006, 2007). Second, I have presented an analysis couched within a specific theory of representation, namely the Parallel Structures Model of feature geometry (Morén 2003, 2006, 2007). Third, I have defended a more general thesis, namely the non-trivial nature of phonological specification.

In the last case, much of my argumentation has been empirical, in that I have shown the challenges met by some previous proposals couched in an approach which sees all phonological specification as more or less trivially derived from the phonetics. However, I have not yet demonstrated the superiority of the PSM. The question is the subject of this section. ${ }^{32}$

The PSM is certainly not the only theory that can provide an empirically accurate account of vowel reduction in Russian. For instance, as discussed in

[3I] I refer to models such as those of Kirchner (1997) or Hale \& Reiss (2008), where representations initially rich in phonetic detail are, in a sense, 'whittled down' to the contrastive details at some later stage. While these aspects of such models are similar to my assumptions here, in that the output of the representational component is subject to the rigours of phonological computation, they still hug the phonetic ground too closely: for instance, as I have shown in this section, nothing in the computational system appears capable of enforcing the [+back] specification on phonetically central [a]. Models that derive that mapping between phonological specifications and their phonetic correlates in the computation, such as that of Boersma \& Hamann (2008) and Boersma (2009), might fare better in this respect; I leave this matter for further research.

[32] I thank two anonymous $J L$ referees for drawing my attention to the necessity of discussing many of the issues that make their appearance in this section. 
the preceding section, such an account can be achieved using relatively orthodox features, even though it requires significant latitude in interpreting the features' possible phonetic content. More to the point, Crosswhite (2000) achieves the same result using only standard Sound-Pattern-of-English-style (SPE-style) features. ${ }^{33}$

I submit that the PSM has a number of significant advantages. They might not seem compelling on the relatively simple set of data such as those found in Russian vowel reduction, but nevertheless they do exist.

One such advantage is privativity. As discussed above, the PSM uses only privative features. With respect to Russian vowel reduction, this enforces one radical departure from SPE-style featural theories: mid vowels must perforce have a special feature that sets them apart from the peripheral vowels. Without recourse to negative values, it is simply impossible to formulate a non-descriptive constraint to militate against mid vowels without recourse to a third factor such as phonetic grounding (Crosswhite 2000) or sonority (de Lacy 2006). However, since the PSM makes the representation of a 'mid vowel' feature available to the computation, it is possible to formulate the relevant constraint in terms of a constraint schema that is independently necessary, namely $*[\mathrm{~F}]$ constraints: as discussed above, no approach to OT assuming Richness of the Base can do without this type of constraint.

The approach employed by Crosswhite (2000) is seemingly simpler: since she makes no commitments to privativity, she can use SPE-style features for the markedness constraint. Moreover, her rankings produce the desired result. Nevertheless, her account is not necessarily more parsimonious. First, as I argued above in Section 3.2, her constraint is essentially descriptive from a purely phonological standpoint. A second, and more serious, objection is relevant for her approach to computation. Instead of IDENT, she follows Zoll (I998a) in using separate MAX and DEP constraints for plus and minus values of features. Given that the rankings for these are independent, her system is in fact much more complex than a privative approach: in effect, instead of a system which only distinguishes between a feature and its absence, the computation operates on pairs of mutually incompatible privative features, of which at least one must always be present. I submit that the PSM approach is conceptually superior, since it does not require these additional stipulations.

A second advantage of PSM arguably lies in its embrace of feature geometry. Specifically, I argued in Section 3.I that an approach based on Unified Feature Theory (Clements I99I, Clements \& Hume 1995) (or approaches that

[33] This can also be said of Mołczanow (2007). Her account, however, is couched within a stratal version of OT in order to account for a number of phenomena that I have argued to lie outside the remit of phonology, namely reduction to 'schwa' and the 'backness switch' phenomenon, see Sections I.2.I and 2.5 respectively. I do not discuss her approach further; in the respects relevant in this section, it is closely similar to Crosswhite's. 


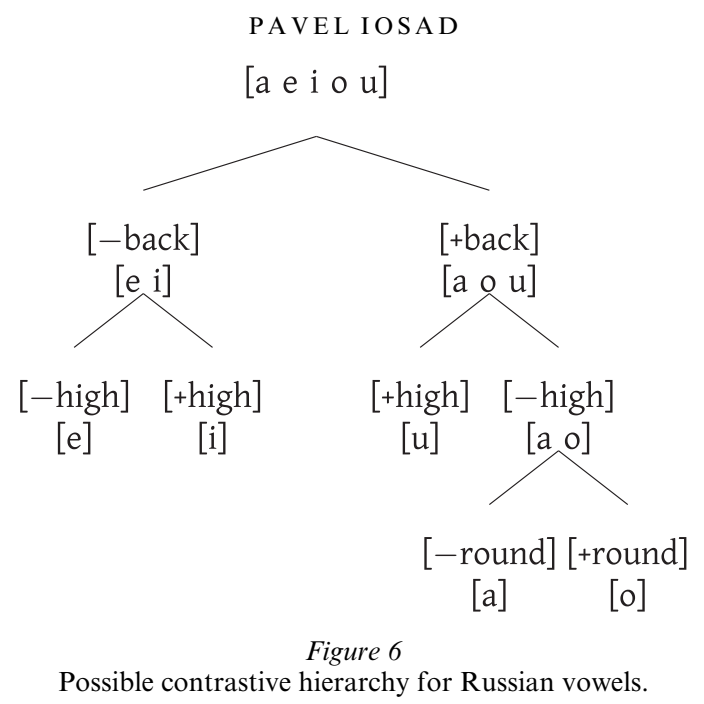

are similar in this respect such as Element Theory) provides a more straightforward account of the association between palatalized consonants and vowel reduction to [i] than a traditional SPE-style feature set.

Nevertheless, it is certainly true that PSM shares both advantages and disadvantages with several other theories, and it remains quite possible that other frameworks allow for a similar account of the Russian data. For instance, Modified Contrastive Specification (e.g. Dresher et al. I994, Hall 2007, Dresher 2009) makes it possible to derive the inventory compatible with the account of Russian data sketched in the previous section by assuming the feature hierarchy shown in Figure 6; it should be possible to do in any theory where the assignment of phonological specifications is based on contrast. I do not believe this detracts from the other major points made in this paper: for instance, even if the solution in Figure 6 is adopted instead of one based on PSM, sufficient latitude must be allowed in the phonetic interpretation of phonological features to interpret phonologically [+ back] [a] as central, which means that non-trivial phonetic implementation is required. ${ }^{34}$

A very important objection against substance-free approaches in general and against the PSM in particular involves their apparent non-restrictiveness. Given that the mapping between phonological representations and phonetic substance is said to be arbitrary, it is trivial to think of systems

[34] The system also suffers from the inability to express the mid vowels as a natural class: this is a common problem in contrast-based SPE-derived featural approaches which do not have a single feature for aperture: in a contrast-based approach, for both [high] and [low] to be contrastive with sufficiently broad scope, the inventory should normally be quite large, which is not the case in Russian. 
which the PSM 'predicts' to be possible but which are unattested (and highly unlikely to be attested) ${ }^{35}$ This problem comes in addition to the "pathologies' that PSM shares by virtue of being embedded in an OT-based computation. For instance, the use of positional faithfulness to implement vowel reduction makes the present account open to the criticism levelled at Crosswhite (200I) by de Lacy (2006): it is predicted that in some languages stress placement may be disrupted in order to protect 'weak' features; in the case of Russian, the weak elements are mid vowels, which produces a typologically implausible pattern (though we have seen that de Lacy's sonoritybased alternative is not without problems).

I believe, however, that, given the wider perspective espoused in this paper, this lack of restrictiveness vis-à-vis standard OT approaches is not necessarily a fatal flaw. The standard OT approach achieves restrictiveness by locating all variation in the constraint ranking and assuming that all other components involved in the computation of phonological symbols are trivial. Yet if we assume that variation is driven by a number of aspects of human linguistic competence, many of which are learned, the attestation of sound patterns becomes influenced by more factors than just the constraint ranking.

One such widely recognized 'filter' is diachrony (Ohala I98I, Kavitskaya 2002, Blevins 2005, Barnes 2006, Yu 2007): a 'crazy' pattern that is predicted to exist by a theory of phonology may be unattested simply because its appearance requires a series of events with very low cumulative probability (see Harris 2008 for an example from morphosyntax). Distinguishing between a pattern that is unattested because it is not permitted by the phonological computation and one that is unattested because it is unlikely to arise, often for 'functional' (phonetic) reasons, is extremely difficult.

Second, as emphasized by Reiss (2007), some languages which the computational system predicts to be possible may be unlearnable. One possible reason is that the ambient data produced by the relevant grammar are indistinguishable (in the relevant respects) from those which lead the acquisition device to always converge on a different mental grammar: for concrete implementation of similar ideas, see Alderete (2008), Heinz (2009).

I suggest, therefore, that while the PSM and similar models may be less restrictive than standard OT approaches with regard to the cardinality of the set of grammars allowed by the theory, the disadvantage is not that great if a substance-free approach is embedded into a more general theory of grammar

[35] For instance, an anonymous $J L$ referee envisages a system where both high and low vowels bear more features than mid vowels, i.e. one which reverses the complexity relationships I propose for Russian. A ranking similar to the one proposed in this paper predicts that both high and low vowels, but not mid ones, will reduce in such a system, which is typologically implausible. 
armed with a better understanding of the functional pressures, learnability mechanisms and consequent diachronic biases that all drive the attestation patterns of phonological phenomena; what disadvantage remains can hopefully be offset by better conceptual and explanatory adequacy. The construction of such a grand theory must of course remain the subject of ongoing research.

Summing up, in this section I have argued that while the use of the Parallel Structures Model is not absolutely necessary to express many of the insights I have proposed in the paper, it nevertheless has a number of important advantages over its competitors. In particular, I have suggested that the set of assumptions labelled 'substance-free phonology', which includes languageparticular phonological representation and an-in principle-arbitrary mapping between phonology and phonetics, is both empirically and conceptually superior to a more traditional approach which sees phonological representations as a trivial 'continuation' of phonetics. If that is so, possible differences in representational formalisms should not detract one of the advantages offered by a substance-free approach as formulated in the present paper.

\section{Conclusion}

The purpose of this paper has been twofold. On the empirical side, I have presented evidence to corroborate the view of Russian vowel reduction first envisaged by Barnes (2006, 2007). I have argued that the 'radical' reduction obtaining in most unstressed syllables does not involve any symbolic computation that is different from that employed in 'moderate' reduction positions.

The data adduced in this paper support Barnes' (2006) proposal with respect to the division of labour between the phonetic and phonological modules of grammar. In his discussion of vowel reduction, Barnes (2006) argues that natural phonetic tendencies, such as those related to the cramping of the vowel space, tend to become phonologized, in that the resultant sound patterns at some point become 'detached' from their original phonetic motivation, and must be accounted for purely in terms of the phonological computation (as proposed by Hyman 1976; see also the discussion in Kingston 2007). The existence of two "vowel reduction' processes in a single language provides further evidence for the independence of the phonetic and phonological modules of grammar (see Bermúdez-Otero 20I0, who calls this phenomenon 'rule scattering', following Robinson 1976).

Thus, I have proposed that a proper understanding of the processes involved in vowel reduction in Russian presupposes a clearer separation between phonetic and phonological phenomena, and a non-trivial phonetics-phonology interface (Keating 1990b, Kingston \& Diehl 1994). Once 
these are in place, the phenomenon of vowel reduction in Russian can be understood in terms of a very simple theory of markedness, as Section 2 demonstrates.

Specifically, I have argued that if phonological representations are set up to reflect the patterning of segments within a given language, the computational operations needed to derive the vowel reduction patterns can be accounted for using very basic faithfulness and markedness constraints on features, rather than reduction-specific constraints making reference to externally grounded phenomena such as sonority or vowel space characteristics. This approach to representations also greatly simplifies the description of the input-output mappings involved in Russian vowel reduction, avoiding many of the pitfalls encountered by a more computationally oriented approach.

Overall, the paper can thus be taken as an argument for a proper division of labour in phonological theory. It presupposes that phonetic factors do not have a direct role to play in much of the phonological computation, that is, that phonology as a grammatical module is largely autonomous and is determined by phonetics only inasmuch as phonological sound patterns are a 'phonologization' of phonetic tendencies (Anderson 198I). On the other hand, the autonomous nature of phonology manifests itself in the assumption that phonological representations are not more or less trivially ' read off' the phonetic substance, but rather are constructed (presumably both by the learner and by the analyst) on the basis of explicit evidence provided by the sound patterns of the language in question (for a similar view, see Mielke 2007). I hope to have shown in this paper that such an approach provides an account of the facts of vowel reduction in Modern Russian that is relatively simple but also avoids many empirical and conceptual pitfalls encountered by a more phonetically-oriented view (as shown in Section 3), and thus to have provided an argument for the superiority of a substance-free approach to phonology.

\section{REFERENCES}

Alderete, John. 1999. Head dependence in stress-epenthesis interaction. In Marc van Oostendorp \& Ben Hermans (eds.), The derivational residue in phonological Optimality Theory (Linguistik Aktuell 28), 29-50. Amsterdam: John Benjamins.

Alderete, John. 2008. Using learnability as a filter on factorial typology: A new approach to Anderson and Browne's generalization. Lingua II 8.8, II 77-I220.

Anderson, John \& Colin Ewen. 1987. Principles of Dependency Phonology. Cambridge: Cambridge University Press.

Anderson, Stephen R. I98I. Why phonology isn't 'natural'. Linguistic Inquiry I2.4, 493-539.

Avanesov, R. I. 1956. Fonetika sovremennogo russkogo jazyka. Moscow: Izdatel'stvo Moskovskogo universiteta.

Barnes, Jonathan. 2006. Strength and weakness at the interface: Positional neutralization in phonetics and phonology. Berlin: Walter de Gruyter.

Barnes, Jonathan. 2007. Phonetics and phonology in Russian unstressed vowel reduction: A study in hyperarticulation. Ms., Boston University.

Beckman, Jill. I999. Positional faithfulness. Ph.D. dissertation, University of Massachusetts Amherst. 


\section{PAVEL IOSAD}

Bermúdez-Otero, Ricardo. 2007. Diachronic phonology. In de Lacy (ed.), 497-518.

Bermúdez-Otero, Ricardo. 20I0. Currently available data on English t/d-deletion fail to refute the classical feedforward modular architecture of phonology. Presented at the i8th Manchester Phonology Meeting.

Bethin, Christina Y. 1998. Slavic prosody: Language change and phonological theory. Cambridge: Cambridge University Press.

Bethin, Christina Y. 2006. Stress and tone in East Slavic dialects. Phonology 23, I25-I56.

Blaho, Sylvia. 2008. The syntax of phonology: A radically substance-free approach. Ph.D. dissertation, University of Tromsø.

Blevins, Juliette. 2005. Evolutionary phonology: The emergence of sound patterns. Cambridge: Cambridge University Press.

Blumenfeld, Lev. 2003. Russian palatalization and Stratal OT: Morphology and [back]. In Wayles Brown, Ji-yung Kim, Barbara Partee \& Robert Rothstein (eds.), Annual Workshop on Formal Approaches to Slavic Linguistics: The Amherst Meeting 2002, I4I-I58. Ann Arbor, MI: Michigan Slavic Publications.

Boersma, Paul. 2009. Cue constraints and their interaction in phonological perception and production. In Paul Boersma \& Silke Hamann (eds.), Phonology in perception, 55-IIO. Berlin: Mouton de Gruyter.

Boersma, Paul \& Silke Hamann. 2008. The evolution of auditory dispersion in bidirectional constraint grammars. Phonology 25, 217-270.

Bondarko, L. V. I977. Zvukovoj stroj sovremennogo russkogo jazyka. Moscow: Prosveščenie.

Bondarko, L. V. \& L. A. Verbickaja. I973. O fonetičeskix xarakteristikax zaudarnyx fleksij v sovremennom russkom jazyke. Voprosy jazykoznanija I, 37-49.

Clements, George N. 199I. Place of articulation in consonants and vowels: A unified theory. Working Papers of the Cornell Phonetics Laboratory 5, 77-I23.

Clements, G[eorge] N. \& Elizabeth V. Hume. 1995. The internal organization of speech sounds. In John Goldsmith (ed.), The handbook of phonological theory, 245-306. Oxford: Blackwell.

Comrie, Bernard, Gerald Stone \& Maria Polinsky. 1996. The Russian language in the twentieth century. Oxford: Clarendon Press.

Crosswhite, Catherine M. 2000. Vowel reduction in Russian: A unified account of standard, dialectal, and 'dissimilative' patterns. In Catherine M. Crosswhite \& Joyce McDonough (eds.), University of Rochester Working Papers in the Language Sciences (Spring 2000), I07-I7I. Rochester, NY: University of Rochester.

Crosswhite, Catherine M. 200I. Vowel reduction in Optimality Theory. London \& New York: Routledge.

de Boer, Bart. 200I. The origins of vowel systems (Oxford Studies in the Evolution of Language I). Oxford: Oxford University Press.

de Lacy, Paul. 2006. Markedness: Reduction and preservation in phonology. Cambridge: Cambridge University Press.

de Lacy, Paul (ed.). 2007. The Cambridge handbook of phonology. Cambridge: Cambridge University Press.

Dresher, B. Elan. 2009. The contrastive hierarchy in phonology. Cambridge: Cambridge University Press.

Dresher, B. Elan, Glyne Piggott \& Keren Rice. 1994. Contrast in phonology: Overview. Toronto Working Papers in Linguistics I4, iii-xvii.

Evans-Romaine, Dorothy Kathleen. 1998. Palatalization and coarticulation in Russian. Ph.D. dissertation, University of Michigan.

Flemming, Edward. 2002. Auditory representations in phonology. London, New York: Routledge.

Fougeron, Cécile \& Patricia A. Keating. 1997. Articulatory strengthening at edges of prosodic domains. Journal of the Acoustical Society of America I0I.6, 3728-40.

Hale, Mark \& Charles Reiss. 2008. The phonological enterprise. Oxford: Oxford University Press.

Hall, Daniel Currie. 2007. The role and representation of contrast in phonological theory. Ph.D. dissertation, University of Toronto.

Hall, Daniel Currie. 20II. Phonological contrast and its phonetic enhancement: Dispersedness without dispersion. Phonology 28.I, I-54. 
Hamann, Silke. 2004. Retroflex fricatives in Slavic languages. Journal of the International Phonetic Association 34.I, 53-67.

Harasowska, Marta. 1999. Morphophonemic variability, productivity, and change: The case of Rusyn (Trends in Linguistics IIO). Berlin: Mouton de Gruyter.

Harris, Alice C. 2008. On the explanation of typologically unusual structures. In Jeff Good (ed.), Linguistic universals and language change, 54-76. Oxford: Oxford University Press.

Harris, John. 1997. Licensing inheritance. Phonology I4.3, 315-370.

Harris, John. 2005. Vowel reduction as information loss. In Philip Carr, Jacques Durand \& Colin J. Ewen (eds.), Headhood, elements, specification, and contrastivity: Papers in honour of John Anderson (Current Issues in Linguistic Theory 259), II9-I32. Amsterdam: John Benjamins.

Harris, John \& Geoff Lindsey. 1995. The elements of phonological representation. In Jacques Durand \& Francis Katamba (eds.), Frontiers of phonology: Atoms, structures, derivations, 34-79. Harlow: Longman.

Heinz, Jeffrey. 2009. On the role of locality in learning stress patterns. Phonology 26.2, 303-35I.

Hermans, Ben. 2008. Russian vowel reduction with elements and without ease of perception. In Gerhild Zybatow, Luka Szucsich, Uwe Junghanns \& Roland Meyer (eds.), Formal Description of Slavic Languages: The Fifth Conference (Linguistik International 20), 92-I04. Frankfurt am Main: Peter Lang.

Honeybone, Patrick. 2006. Disagreeing with Agree. Presented at OCP [Old World Conference in Phonology] 3, Budapest, Hungary.

Hyman, Larry M. 1976. Phonologization. In Alphonse Juilland (ed.), Linguistic studies presented to Joseph H. Greenberg, 407-4I8. Saratoga, CA: Anna Libri.

Iosad, Pavel \& Bruce Morén-Duolljá. 20I2. Russian palatalization: A holistic approach. Ms., University of Tromsø/CASTL.

Jones, Daniel \& Dennis Ward. 1969. The phonetics of Russian. Cambridge: Cambridge University Press.

Kamprath, Christine. 1987. Suprasegmental structures in a Raeto-Romansh dialect: A case study of metrical and lexical phonology. Ph.D. dissertation, The University of Texas at Austin.

Kasatkin, L. L. 2003. Fonetika sovremennogo russkogo literaturnogo jazyka. Moscow: Izdatel'stvo Moskovskogo universiteta.

Kasatkina, R. F. 2005. Moskovskoje akan'je v svete nekotoryx dialektnyx dannyx. Voprosy jazykoznanija 2, 29-45.

Kavitskaya, Darya. 2002. Compensatory lengthening: Phonetics, phonology, diachrony. London $\&$ New York: Routledge.

Keating, Patricia A. 1987. Acoustic study of Russian vowel allophones. Journal of the Acoustical Society of America 8ISI, S67-S68.

Keating, Patricia A. 1988. Underspecification in phonetics. Phonology 5, 275-292.

Keating, Patricia A. 1990a. The window model of coarticulation: Acoustic evidence. In John Kingston \& Mary Beckman (eds.), Papers in Laboratory Phonology I: Between the grammar and physics of speech, 45I-470. Cambridge: Cambridge University Press.

Keating, Patricia A. I990b. Phonetic representations in a generative grammar. Journal of Phonetics I8, 32I-334.

Keating, Patricia A. 1996. The phonology-phonetics interface. In Ursula Kleinhenz (ed.), Interfaces in phonology (Studia Grammatica 4I), 262-278. Berlin: Akademie Verlag.

Kingston, John. 2007. The phonetics-phonology interface. In de Lacy (ed.), 40I-434.

Kingston, John \& Randy L. Diehl. I994. Phonetic knowledge. Language 70.3, 4I9-454.

Kirchner, Robert. I997. Contrastiveness and faithfulness. Phonology I4.I, 83-III.

Kniazev, S. V. 2006. Struktura fonetičeskogo slova v russkom yazyke: sinxronija i diaxronija. Moscow: MAKS-press.

Kniazev, S. V. \& S. K. Požarickaya. 2005. Sovremennyj russkij literaturnyj jazyk: fonetika, grafika, orfografija, orfoepija. Moscow: Akademičeskij proekt.

Kochetov, Alexei. 2002. Production, perception and emergent phonotactic patterns. London \& New York: Routledge.

Likhtman, R. I. I999. O foneme $<\mathrm{u}>\mathrm{v}$ sovremennom russkom literaturnom jazyke. Problemy fonetiki, $\mathrm{I} 2 \mathrm{I}-\mathrm{I} 32$. 
Lodge, Ken. 2009. Fundamental concepts in phonology: Sameness and difference. Edinburgh: University of Edinburgh Press.

Lutta, C. Martin. 1923. Der Dialekt von Bergün und seine Stellung innerhalb der rätoromanischen Mundarten Graubündens (Beihefte zur Zeitschrift für romanische Philologie 7I). Halle an der Saale: Verlag Max von Niemeyer.

McCarthy, John J. 2008. The gradual path to cluster simplification. Phonology 25.2, 27I-319.

McCarthy, John J. 2009. Harmony in Harmonic Serialism. Ms., University of Massachusetts Amherst. [ROA-I009]

Mielke, Jeff. 2007. The emergence of distinctive features. Oxford: Oxford University Press.

Morén, Bruce. 200I. Distinctiveness, coercion, and sonority: A unified theory of weight. London \& New York: Routledge.

Morén, Bruce. 2003. The Parallel Structures model of feature geometry. Working Papers of the Cornell Phonetics Laboratory I5, 194-270.

Morén, Bruce. 2006. Consonant-vowel interactions in Serbian: Features, representations and constraint interactions. Lingua II6, II98-I244.

Morén, Bruce. 2007. The division of labour between segment-internal structure and violable constraints. In Sylvia Blaho, Patrik Bye \& Martin Krämer (eds.), Freedom of analysis? (Studies in Generative Grammar 95), 313-344. Berlin: Mouton de Gruyter.

Mołczanow, Janina. 2007. Russian vowel reduction and phonological opacity. Slavonic and East European Review 85.2, 20I-230.

Nesset, Tore. 2008. Ob'jasnenie togo, čto ne imelo mesta: blokirovka suffiksal'nogo sdviga $\mathrm{v}$ russkix glagolax. Voprosy jazykoznanija 6, 35-48.

Ohala, John J. 1978. Production of tone. In Victoria A. Fromkin (ed.), Tone: A linguistic survey, 5-39. New York: Academic Press.

Ohala, John J. 198I. The listener as the source of sound change. Chicago Linguistics Society (CLS) I7, I78-203.

Padgett, Jaye. 200I. Contrast dispersion and Russian palatalization. In Elizabeth V. Hume \& Keith Johnson (eds.), The role of speech perception in phonology, I87-218. San Diego, CA: Academic Press.

Padgett, Jaye. 2003. Contrast and post-velar fronting in Russian. Natural Language \& Linguistic Theory 2I.I, 39-87.

Padgett, Jaye. 2004. Russian vowel reduction and Dispersion Theory. Phonological Studies 7 , $8 \mathrm{I}-96$.

Padgett, Jaye. 20II. Russian consonant-vowel interactions and derivational opacity. In Wayles Brown, Adam Cooper, Alison Fisher, Esra Kesici, Nikola Predolac \& Draga Zec (eds.), Formal Approaches to Slavic Linguistics I8: The Second Cornell Meeting 2009, 352-38I, Ann Arbor, MI: Michigan Slavic Publications.

Padgett, Jaye \& Marija Tabain. 2005. Adaptive Dispersion Theory and phonological vowel reduction in Russian. Phonetica 62, I4-54.

Padgett, Jaye \& Marzena Żygis. 2007. The evolution of sibilants in Polish and Russian. Journal of Slavic Linguistics I5.2. 29I-324.

Paufošima, R. F. I980. Aktivnye processy v sovremennom russkom literaturnom jazyke: assimilyativnye izmenenija bezudarnyx glasnyx. Izvestija Akademii Nauk SSSR (Serija literatury i jazyka 39.I), 6I-68. Moscow: Akademia Nauk SSSR.

Plapp, Rosemary Kuhn. 1996. Russian /i/ and /i/ as underlying segments. Journal of Slavic Linguistics 4, 76-108.

Plapp, Rosemary Kuhn. 1999. Lexical Phonology and Optimality Theory: Analysis of Russian. Ph.D. dissertation, University of Iowa.

Potts, Christopher, Joe Pater, Karen Jesney, Rajesh Bhatt \& Michael Becker. 20Io. Harmonic Grammar with linear programming: From linear systems to linguistic typology. Phonology 27.I, 77-II7.

Prince, Alan. 2002. Arguing optimality. In Angela Carpenter, Andries Coetzee \& Paul de Lacy (eds.), Papers in Optimality Theory II (University of Massachusetts Occasional Papers in Linguistics), 269-394. Amherst, MA: Graduate Linguistic Student Association (GLSA).

Reiss, Charles. 2007. Modularity in the sound domain: Implications for the purview of Universal Grammar. In Charles Reiss \& Gillian Ramchand (eds.), The Oxford handbook of linguistic interfaces, 53-80. Oxford: Oxford University Press. 
Robinson, Orrin Warner. 1976. A 'scattered' rule in Swiss German. Language 52.I, I48-62.

Rubach, Jerzy. 2000. Backness switch in Russian. Phonology 17, 39-64.

Rubach, Jerzy. 2007. Feature geometry from the perspective of Polish, Russian, and Ukrainian. Linguistic Inquiry 38.I, 85-I38.

Steriade, Donca. 1993. Orality and markedness. Berkeley Linguistics Society (BLS) 25, 334-337.

Timberlake, Alan. 2004. A reference grammar of Russian. Cambridge: Cambridge University Press.

Tomson, A. I. 1905. Fonetičeskie etyudy (Russkij filologičeskij vestnik 2). Warsaw.

Trubetzkoy, Nikolai Sergejevič. 1939. Grundzüge der Phonologie (Travaux du Cercle lingquistique de Prague 7). Prague: Le cercle linguistique de Prague.

Walker, Rachel. 2005. Weak triggers in vowel harmony. Natural Language \& Linguistic Theory 23.4, 9I7-989.

Wolf, Matthew. 2008. Optimal interleaving: Serial phonology-morphology interaction in a constraint-based model. Ph.D. dissertation, University of Massachusetts Amherst.

Youssef, Islam. 2010. Laryngeal assimilation in Buchan Scots. English Language and Linguistics I4.3, 32I-345.

Yu, Alan C. L. 2007. A natural history of infixation. Oxford: Oxford University Press.

Zoll, Cheryl. I998a. Parsing below the segment in a constraint-based framework. Stanford, CA: CSLI Publications.

Zoll, Cheryl. 1998b. Positional faithfulness and licensing. Ms., MIT. [ROA-282]

Zubritskaya, Katya. 1997. Mechanism of sound change in Optimality Theory. Language Variation and Change 9.I, I2I-I48.

Author's address : Center for Advanced Study in Theoretical Linguistics,

University of Tromso, 9037 Tromsø, Norway

pavel.iosad@uit.no 